Atmos. Chem. Phys., 13, 9379-9400, 2013

www.atmos-chem-phys.net/13/9379/2013/

doi:10.5194/acp-13-9379-2013

(c) Author(s) 2013. CC Attribution 3.0 License.

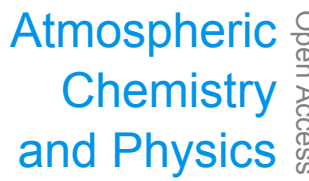

\title{
Cloud and boundary layer interactions over the Arctic sea ice in late summer
}

\author{
M. D. Shupe ${ }^{1}$, P. O. G. Persson ${ }^{1}$, I. M. Brooks² ${ }^{2}$ M. Tjernström ${ }^{3}$, J. Sedlar ${ }^{4}$, T. Mauritsen ${ }^{5}$, S. Sjogren ${ }^{6}$, and C. Leck ${ }^{3}$ \\ ${ }^{1}$ Cooperative Institute for Research in Environmental Sciences, University of Colorado and NOAA-Earth System Research \\ Laboratory, Boulder, CO, USA \\ ${ }^{2}$ Institute for Climate and Atmospheric Science, University of Leeds, Leeds, UK \\ ${ }^{3}$ Department of Meteorology and the Bert Bolin Centre for Climate Research, Stockholm University, Stockholm, Sweden \\ ${ }^{4}$ Swedish Meteorological and Hydrological Institute, Norrköping, Sweden \\ ${ }^{5}$ Max Plank Institute for Meteorology, Hamburg, Germany \\ ${ }^{6}$ Department of Physics, Lund University, Lund, Sweden
}

Correspondence to: M. D. Shupe (matthew.shupe@noaa.gov)

Received: 18 April 2013 - Published in Atmos. Chem. Phys. Discuss.: 17 May 2013

Revised: 17 July 2013 - Accepted: 8 August 2013 - Published: 24 September 2013

\begin{abstract}
Observations from the Arctic Summer Cloud Ocean Study (ASCOS), in the central Arctic sea-ice pack in late summer 2008, provide a detailed view of cloudatmosphere-surface interactions and vertical mixing processes over the sea-ice environment. Measurements from a suite of ground-based remote sensors, near-surface meteorological and aerosol instruments, and profiles from radiosondes and a helicopter are combined to characterize a weeklong period dominated by low-level, mixed-phase, stratocumulus clouds. Detailed case studies and statistical analyses are used to develop a conceptual model for the cloud and atmosphere structure and their interactions in this environment.

Clouds were persistent during the period of study, having qualities that suggest they were sustained through a combination of advective influences and in-cloud processes, with little contribution from the surface. Radiative cooling near cloud top produced buoyancy-driven, turbulent eddies that contributed to cloud formation and created a cloud-driven mixed layer. The depth of this mixed layer was related to the amount of turbulence and condensed cloud water. Coupling of this cloud-driven mixed layer to the surface boundary layer was primarily determined by proximity. For $75 \%$ of the period of study, the primary stratocumulus cloud-driven mixed layer was decoupled from the surface and typically at a warmer potential temperature. Since the near-surface temperature was constrained by the ocean-ice mixture, warm temperatures aloft suggest that these air masses had not sig-
\end{abstract}

nificantly interacted with the sea-ice surface. Instead, backtrajectory analyses suggest that these warm air masses advected into the central Arctic Basin from lower latitudes. Moisture and aerosol particles likely accompanied these air masses, providing necessary support for cloud formation. On the occasions when cloud-surface coupling did occur, back trajectories indicated that these air masses advected at low levels, while mixing processes kept the mixed layer in equilibrium with the near-surface environment. Rather than contributing buoyancy forcing for the mixed-layer dynamics, the surface instead simply appeared to respond to the mixedlayer processes aloft. Clouds in these cases often contained slightly higher condensed water amounts, potentially due to additional moisture sources from below.

\section{Introduction}

In recent years it has become apparent that the Arctic climate is changing more rapidly and extremely than other locations on the globe (Holland and Bitz, 2003; Serreze et al., 2009), a change that is embodied by drastic decreases in sea-ice amount (Stroeve et al., 2007, 2012; Comiso et al., 2008). Some of these changes have been either directly or indirectly linked to clouds (Francis and Hunter, 2006; Kay et al., 2008; Liu et al., 2008; Perovich et al., 2008; Kay and Gettelman, 2009; Vavrus et al., 2011), although the mechanisms 
and feedbacks involved in these linkages are not necessarily clear. Fractional cloud occurrence appears to also be changing in some seasons (Wang and Key, 2003; Liu et al., 2007; Schweiger et al., 2008). Clouds, and particularly low-level, stratiform, liquid-containing clouds, strongly influence the surface energy budget by modulating the flow of energy through the atmosphere-surface system (e.g., Shupe and Intrieri, 2004). For example, when opaque clouds occur over sea ice there is typically a net increase in surface longwave radiation of $40 \mathrm{~W} \mathrm{~m}^{-2}$ or more (e.g., Persson et al., 2002; Stramler et al., 2011; Morrison et al., 2012). Thus, a relatively small change in the fractional occurrence of opaque clouds can significantly affect the surface energy budget and thus the sea-ice mass budget. Using climate model simulations, Vavrus (2004) attributed about $40 \%$ of Arctic warming resulting from $\mathrm{CO}_{2}$-doubling experiments to changes in clouds and cloud feedbacks. However, models struggle to faithfully represent Arctic clouds, particularly those that contain liquid water (Tjernström et al., 2008; Karlsson and Svensson 2011; Barton et al., 2012; Birch et al., 2012; de Boer et al., 2012).

The low-level, liquid-containing clouds that are of particular interest here occur frequently in the Arctic. Observations at Arctic coastal observatories and over the sea ice indicate that liquid water occurs in all seasons, reaching a maximum occurrence fraction of 50-90\% in autumn depending on location (Shupe, 2011; Cesana et al., 2012). These high occurrence fractions are in large part due to the persistent nature of stratiform clouds (Shupe et al., 2006; Shupe, 2011), which are frequently mixed phase, containing both supercooled liquid water and ice. Thus, when considering the overall distribution of these clouds in the Arctic, it is critical to understand how and why they persist in a variety of locations and whether the conditions that support this persistence are subject to change as the Arctic climate changes.

Arctic low-level, stratiform, liquid-containing clouds persist via a complex web of interdependent processes, many of which are primarily internal to the cloud system (e.g., Morrison et al., 2012). Many of these processes comprise positive feedbacks that sustain supercooled liquid water in spite of a near-continuous sink of condensate via ice precipitation. For example, due to its typical microphysical composition, cloud liquid water is effective at emitting longwave radiation to space (e.g., Pinto, 1998), which destabilizes the cloud-top environment and leads to bouyancy-driven, turbulent overturning within a mixed layer associated with the cloud (e.g., Nicholls, 1984; Solomon et al., 2011). In turn these turbulent motions promote further cloud growth. While processes such as ice formation modulate the growth of cloud liquid, ice growth from within the cloud itself is typically not strong enough to fully glaciate the cloud layer allowing liquid water to persist.

There exist a variety of unknowns in this low-level Arctic cloud system related to the source and role of aerosol particles, the impact of large-scale advection, and the ener- getic and moisture linkages with the surface. For example, it is unclear if the aerosol particles that are required for both cloud liquid droplets and ice particles to form are advected into the central Arctic from lower-latitude marginal ice zone or ice-free regions (e.g., Li et al., 1993; Leck and Persson 1996; Chang et al., 2011) or if local sources play a critical role (e.g., Levasseur et al., 1994; Leck et al., 2002; Leck and Bigg, 2005; Orellana et al., 2011). Additionally, the importance of surface sources of heat and moisture in promoting cloud processes relative to in-cloud or advective sources is uncertain (e.g., Curry and Herman, 1985; Jiang et al., 2000; Morrison et al., 2012). These unknowns comprise critical gaps in our process-level understanding of these important clouds and the manner in which they may respond to further changes in sea-ice concentrations, moisture availability, temperature, aerosol populations, and other factors. Importantly, many of these unknowns are intimately linked to the vertical distribution, transport, and mixing of various quantities in the Arctic atmospheric system.

Observations of low-level, stratiform clouds over the central Arctic sea ice have been extremely sparse, particularly those that are detailed enough to provide a simultaneous characterization of the primary processes through which the cloud, atmospheric boundary layer, and surface interact. A variety of past aircraft campaigns over the sea ice have contributed significantly to our knowledge of this system (Herman and Curry, 1984; Hobbs and Rangno, 1998; Curry et al., 2000; Verlinde et al., 2007; McFarquhar et al., 2011). However, the aircraft perspective does not offer coordinated information on the vertical atmosphere-cloud-surface structure and how it evolves in time. The Surface Heat Budget of the Arctic Ocean (SHEBA; Uttal et al., 2002) project, with its suite of ground-based remote sensors operated from an icebreaker in the Beaufort and Chukchi seas, gave the first view into the evolving vertical structure of this system over an entire year, and the properties of the clouds associated with it (Shupe et al., 2006). However, SHEBA was also limited in important ways, with measurements that were unable to sufficiently characterize boundary layer winds, turbulence, and vertical structure and had virtually no information on aerosol concentrations or properties.

More recently a pair of shorter-term research expeditions targeting cloud and atmosphere processes in the central Arctic have been conducted using the Swedish icebreaker Oden. The Arctic Ocean Expedition of August 2001 (AOE-2001; Leck et al., 2004; Tjernström et al., 2004) involved many of the important instruments operated during SHEBA, with the addition of higher-resolution atmospheric sounding capabilities and a full complement of near-surface aerosol measurements. AOE-2001 provided a detailed characterization of the shallow boundary layer over autumn sea ice, with frequent moisture inversions contributing to persistent cloudiness (Tjernström, 2005). Long-range transport was found to be an important source of heat and moisture aloft, but the 
Table 1. Instruments, with pertinent specifications and derived products.

\begin{tabular}{|c|c|c|}
\hline Instrument & Specifications & Derived Products \\
\hline Millimeter Cloud Radar (MMCR) & $35 \mathrm{GHz}$; vertically pointing; Doppler & $\begin{array}{l}\text { Cloud top height, IWC, IWP, } w, w \text { skew- } \\
\text { ness, } \varepsilon \text {, mixed-layer base }\end{array}$ \\
\hline Ceilometer & Vertically pointing & Cloud base height \\
\hline Microwave radiometer (MWR) & 23 and $30 \mathrm{GHz}$; vertically pointing & LWP \\
\hline Microwave profiler & $60 \mathrm{GHz}$; elevation scanning & $\theta$ up to $1.2 \mathrm{~km}$ \\
\hline Wind profiler & $449 \mathrm{MHz}$ & Winds to $2-5 \mathrm{~km}$ \\
\hline Radiosondes & 6-hourly & Temperature, $\mathrm{RH}, \theta_{E}, q_{v}$ \\
\hline Meteorological tower & $\begin{array}{l}\text { Sonic anemometer, licor, and meteorolog- } \\
\text { ical measurements at multiple heights up } \\
\text { to } 30 \mathrm{~m}\end{array}$ & $\begin{array}{l}\text { Near-surface sensible and latent heat } \\
\text { fluxes }\end{array}$ \\
\hline Meteorological package & Onboard Oden & Temperature, $\mathrm{RH}$ \\
\hline $\begin{array}{l}\text { Marine-Atmospheric Emitted Radiance } \\
\text { Interferometer (MAERI) }\end{array}$ & $\begin{array}{l}\text { Multi-angle viewing; spectral IR radi- } \\
\text { ances }\end{array}$ & Temperature at surface and aloft \\
\hline $\begin{array}{l}\text { Twin differential mobility particle sizer } \\
\text { (TDMPS) }\end{array}$ & 3-800 $\mathrm{nm}$ size range; $25-\mathrm{m}$ inlet height & $\begin{array}{l}\text { Aerosol concentration for sizes }>100 \text { and } \\
>300 \mathrm{~nm}\end{array}$ \\
\hline $\begin{array}{l}\text { Cloud condensation nucleus counter } \\
(\mathrm{CCNC})\end{array}$ & $\begin{array}{l}\text { Continuous-flow, stream-wise thermal } \\
\text { gradient; } 25-\mathrm{m} \text { inlet height }\end{array}$ & $\begin{array}{l}\mathrm{CCN} \text { concentration at } 0.2 \% \text { supersatura- } \\
\text { tion }\end{array}$ \\
\hline $\begin{array}{l}\text { Compact Lightweight Aerosol Spectrom- } \\
\text { eter Probe (CLASP) }\end{array}$ & $\begin{array}{l}300 \mathrm{~nm}-18 \mu \mathrm{m} \text { size range; helicopter } \\
\text { mounted }\end{array}$ & Aerosol concentration for sizes $>300 \mathrm{~nm}$ \\
\hline
\end{tabular}

relatively strong boundary layer stratification buffered the surface environment from free-tropospheric influences.

Building on, and expanding from, AOE-2001 was the Arctic Summer Cloud Ocean Study in August 2008 (ASCOS; Tjernström et al., 2012, 2013). ASCOS included arguably the most comprehensive suite of instruments to date that have been deployed in the high Arctic sea ice for observing surface processes and the vertical structure of the atmosphere and clouds. In particular, these included enhanced cloud radar observations, a tethered-sonde profiling system, a full aerosol suite near the surface, and aerosol and atmospheric profiling from a helicopter. While the full ASCOS cruise lasted from 2 August to 9 September 2008, an ice camp was established from 12 August to 2 September whereby the Oden was moored to, and drifted with, an ice floe embedded in the ice pack near $87^{\circ} \mathrm{N}$ and between 1 and $11^{\circ} \mathrm{W}$ (Fig. 1). All observations included in this paper were made towards the end of the drifting ASCOS ice station, when a nearly continuous deck of stratiform mixed-phase clouds persisted above the site for a full week (e.g., Sedlar et al., 2011).

By examining these stratiform mixed-phase clouds during ASCOS, this study aims to elucidate many of the processes that link the cloud-atmosphere-surface system within the Arctic sea-ice environment. Of particular focus is the role of clouds in vertical mixing processes that shape the low-level atmospheric structure and transport atmospheric constituents. While it is clear that observations from a single week in late August at a single location in the Arctic ice pack are likely not representative of cloud-atmospheresurface processes across the Arctic Basin at all times of year, the ASCOS observations provide a unique opportunity to ex- amine these processes in depth. Moreover, the clouds observed at this time were structurally similar to Arctic mixedphase clouds observed at SHEBA (Turner, 2005; Shupe et al., 2006), Barrow, Alaska (Verlinde et al., 2007; Shupe et al., 2008), Eureka, Canada (de Boer et al., 2009), Summit, Greenland (Shupe et al., 2013), and elsewhere. Thus, insight gained from ASCOS complements information from these other sites towards developing a more comprehensive understanding of these important clouds. Lastly, these low-level stratiform clouds at ASCOS happened to occur during the fall transition towards sea-ice freeze-up (Sedlar et al., 2011), such that the processes considered here had particular relevance to this important seasonal transition in sea-ice energy budgets.

\section{Observations and methods}

The ASCOS instrument suite has been documented in detail by Tjernström et al. (2013). Key instruments used in this study are summarized in Table 1, while important measurement details are discussed below within the context of derived geophysical parameters. Many of these same instruments have been deployed collectively at other Arctic sites, such that the methods used here have been employed successfully in similar conditions. These methods will be briefly described, with additional support information contained in cited references. 


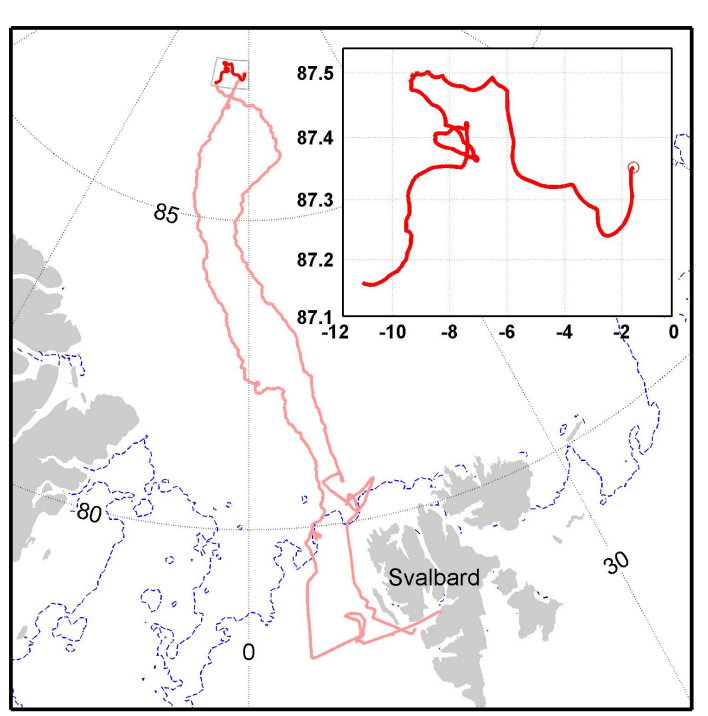

Fig. 1. Cruise and drift (inset) track of Oden during ASCOS. The sea-ice edge is denoted by the blue dots.

\subsection{Cloud microphysical and macrophysical properties}

Cloud base height was observed using standard Vaisala ceilometer measurements, while cloud top was measured using a Ka-band, Doppler, Millimeter Cloud Radar (MMCR; Moran et al., 1998). The shallow clouds considered here have a negligible attenuation effect on radar observations, such that cloud top is relatively robust to within the radar rangegate length of $45 \mathrm{~m}$. Cloud base represents the base of the liquid cloud layer; only in cases of very heavy precipitation and/or the presence of atmospheric ice without liquid water is there some ambiguity in the ceilometer-measured cloud base. In those cases, the base is located at the point of significant obscurity of the signal. Cloud phase was determined using the multi-sensor approach of Shupe (2007), although in this case the ceilometer cloud base height was used in place of depolarization lidar measurements. Fortunately, the cloud structure during the period of study was relatively simple to diagnose from other instruments and all phase classifications were manually screened to ensure consistency.

Cloud liquid water path (LWP) was derived from microwave radiometer measurements at 23 and $30 \mathrm{GHz}$. The uncertainty for these retrievals is nominally $25 \mathrm{~g} \mathrm{~m}^{-2}$ (Westwater et al., 2001), which can be significant when observed liquid water amounts are small $\left(<50 \mathrm{~g} \mathrm{~m}^{-2}\right)$. Vertical profiles of cloud ice water content (IWC) were derived from radar reflectivity using a season-specific, empirically derived power law regression developed from similar observations over the Arctic sea ice (Shupe et al., 2005). During this time period, the power law used was IWC $=0.064 \mathrm{Z}_{e}^{0.63}$, where $\mathrm{Z}_{e}$ is in $\mathrm{mm}^{6} \mathrm{~m}^{-3}$ and IWC is in $\mathrm{g} \mathrm{m}^{-3}$. The uncertainty for this type of retrieval is estimated to be approximately a factor of two
(Shupe et al., 2005). The vertical integral of IWC, or the ice water path (IWP), is also considered here.

\subsection{Cloud dynamics}

For atmospheric volumes identified to contain liquid cloud droplets, vertical air motion $(w)$ was estimated from $4 \mathrm{~s}$ radar measurements by relying on the fact that small liquid droplets have a terminal fall speed that is negligible relative to vertical air motions. The slowest falling edge of vertically pointing cloud radar Doppler spectra represents these liquid droplets and provides an initial estimate of their motion, and thus the air motion (Shupe et al., 2008). This initial estimate is biased from the true vertical velocity by Doppler spectrum broadening due to turbulence and shear in the pulse volume, and other factors. To minimize this bias, a running $30 \mathrm{~min}$ mean velocity was removed under the assumption that over 30 min periods the vertical air motion at a given height will be zero. This short-pass filter does not impact cloud-scale motions, which typically occur on scales less than $10 \mathrm{~min}$, but does remove larger motions occurring at meso- to synoptic scales. These motions are typically $<5 \mathrm{~cm} \mathrm{~s}^{-1}$, which is small relative to in-cloud turbulent vertical motions, and the extent to which they were actually present will contribute to uncertainty in vertical velocity estimates. From these estimates, the vertical velocity variance and skewness were computed over $30 \mathrm{~min}$ running windows of 3 adjacent vertical range gates.

In addition to vertical motions, the temporal variance of radar-measured Doppler velocity is related to the turbulent dissipation rate ( $\varepsilon$; e.g., Bouniol et al., 2003; Shupe et al., 2008). This retrieval requires hydrometeors (liquid or ice) to be present within the radar pulse volume and is only possible above the lowest observable radar height of $0.15 \mathrm{~km}$. A comparison of this retrieval with $\varepsilon$ derived from sonic anemometers mounted on a tethered balloon and a meteorological tower at ASCOS indicates that differences between radarbased retrievals and tethered balloon-based estimates are no larger than differences between estimates from tethered balloon and tower-mounted measurements (Shupe et al., 2012). Root mean square differences among these sources are a factor of 4-6, which represents uncertainty in the derivation and differences over spatial scales of a couple hundred meters that separated the instruments. The radar-derived $\varepsilon$ is used here as a qualitative proxy for the vertical structure of atmospheric turbulence. One benefit of the radar-based perspective is that it offers continuous information on atmospheric turbulence when hydrometeors are present and can be related to coincident information on cloud, atmosphere, and surface processes.

An additional parameter derived from the $\varepsilon$ product was the base height of the cloud-driven mixed layer. For instantaneous profiles that contained precipitating ice crystals, the mixed-layer base was defined as the highest height below cloud base at which $\varepsilon$ fell below a threshold of 
$5 \times 10^{-5} \mathrm{~m}^{2} \mathrm{~s}^{-3}$. To capture the upper mixed layer in cases when near-surface fogs were present, the "cloud base" used in this calculation was allowed to be no more than $0.4 \mathrm{~km}$ below cloud top. The $\varepsilon$ threshold used here was designed, based on experience with multiple data sets, to distinguish turbulent environments from non-turbulent environments. Threshold values over the range of $3 \times 10^{-5}$ to $1 \times 10^{-4} \mathrm{~m}^{2} \mathrm{~s}^{-3}$ were tested and, while the mixed-layer bases changed accordingly, the primary results from this study were not significantly affected. If the mixed-layer base was not identified above $0.15 \mathrm{~km}$, then it was assumed to be linked to the surfacebased mixed layer below. For time series plotting purposes, the mixed-layer base height has been smoothed over running 6 min windows.

\subsection{Thermodynamic structure}

Vertical profiles of conserved properties such as equivalent potential temperature $\left(\theta_{E}\right)$ can be used to identify atmospheric layers that are well mixed. Radiosondes were launched at least every $6 \mathrm{~h}$ during ASCOS, providing a highquality, 6-hourly data set of temperature, moisture, and wind profiles. Complementary potential temperature $(\theta)$ profiles at 5 min time resolution were also derived from a scanning, 60GHz radiometer (Westwater et al., 1999). $\theta$ is not conserved in saturated adiabatic processes and will increase as condensation occurs. This $60-\mathrm{GHz}$ retrieval is strongly influenced by an a priori temperature field derived from interpolated radiosonde measurements. While the influence of the a priori field is apparent in derived products, evaluations of the retrieval performed by removing specific radiosondes from the a priori data set indicate that the retrieval provides additional information up to $0.7 \mathrm{~km}$ beyond simple interpolation of radiosonde measurements. Lastly, vertical profiles of horizontal wind speed and direction were measured by a $449-\mathrm{MHz}$ wind profiler; ASCOS was the first time that such a wind profiler was deployed in the central Arctic. Measurements from the wind profiler were averaged over $30 \mathrm{~min}$ time windows in order to get a sufficient signal at heights of up to $3 \mathrm{~km}$ or more.

\subsection{Surface fluxes}

Surface turbulent heat fluxes were derived from towermounted sonic anemometers, open-path gas analyzers, and high-resolution temperature measurements made at various heights up to $30 \mathrm{~m}$ over the sea ice adjacent to Oden (Sedlar et al., 2011). Eddy covariance techniques were applied using standard data editing techniques with prescribed thresholds, producing $5 \mathrm{~min}$ values of stress and sensible heat flux. The surface-layer sensible heat flux was estimated as the median of accepted heat flux values from six heights, producing a time series to which a 25 min running mean was applied. Due to instrument problems, the covariance latent heat fluxes were unusable. However, near-surface fluxes were also estimated using a bulk technique combining measurements from the Marine-Atmospheric Emitted Radiance Interferometer (MAERI) and a weather station, both located on Oden's 7th deck (see Tjernström et al., 2012). MAERI infrared radiances provided an air temperature at $21 \mathrm{~m}$ above the surface perpendicular to the ship and a surface temperature when looking at an angle down towards the surface. When combined with observed humidity and wind speed, bulk momentum, sensible, and latent heat fluxes were computed using a bulk flux scheme adapted for Arctic sea-ice conditions (Persson et al., 2002). Surface relative humidity was assumed to be $100 \%$ with respect to ice. Bulk momentum and sensible heat fluxes agree reasonably well with their covariance counterparts, suggesting that bulk latent heat fluxes are reasonable. Only the covariance sensible heat fluxes and bulk latent heat fluxes are used here.

\subsection{Aerosol number concentrations}

Near-surface aerosol measurements were made from an inlet with an impactor $50 \%$ cutoff diameter of $10 \mu \mathrm{m}\left(\mathrm{PM}_{10}\right)$ at 25-m height onboard Oden (Tjernström et al., 2013). Aerosol particle number size distributions at 10 to $20 \mathrm{~min}$ time resolution were measured in 45 bins from 3 to $800 \mathrm{~nm}$ (all aerosol sizes are for particle diameter) using a twin differential mobility particle sizer (TDMPS; Birmili et al., 1999). Using these size distributions, particle concentrations for all sizes larger than $100 \mathrm{~nm}\left(N_{>100}\right)$ and $300 \mathrm{~nm}\left(N_{>300}\right)$ were calculated for use here. Aerosol particles that are active as cloud condensation nuclei (CCN) were measured continuously using a CCN counter (Roberts and Nenes, 2005) operating at a fixed supersaturation of $\sim 0.2 \%$. Generally, larger aerosol particles are more active as $\mathrm{CCN}$; indeed $N_{>100}$ was typically similar to the independently measured CCN concentration. The quality of all ship-board aerosol sampling was monitored using various tracers and thresholds to identify potential contamination from local ship and snowmobile pollution. Further details on the quality and data processing of ship-based aerosol and CCN measurements are available in Heintzenberg and Leck (2012) and Martin et al. (2011), respectively.

Vertical profiles of aerosol concentrations were made using a helicopter (Kupiszewski et al., 2013). All helicopter sampling was designed to eliminate impacts from rotor down wash, and flights were flown perpendicular to prevailing winds to ensure pollution-free sampling. Aerosol concentrations for particles in the size range of $300 \mathrm{~nm}$ to $18 \mu \mathrm{m}$ (i.e., $N_{>300}$ ) were obtained using the Compact Lightweight Aerosol Spectrometer Probe (CLASP; Hill et al., 2008). While CCN were not measured onboard the helicopter, it is clear from near-surface measurements that $N_{>300}$ is highly correlated with, albeit less than, CCN concentrations. Due to the risk of icing conditions, the helicopter was not flown through cloud, although it often sampled up to, and slightly 

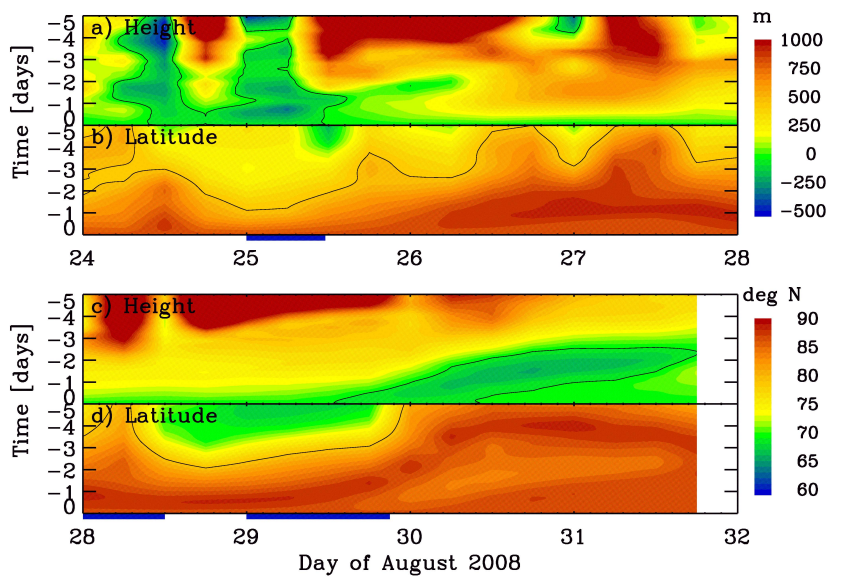

Fig. 2. Five-day back trajectories for an arrival height at Oden of $0.5 \mathrm{~km}$, including (a, c) the trajectory height relative to $0.5 \mathrm{~km}$, and (b, d) the trajectory latitude. Two different 4-day periods from the end of August are plotted. The black contour in (a) and (c) designates a height of $0 \mathrm{~km}$ (i.e., no height change), while the black contour in (b) and (d) designates a latitude of $80^{\circ} \mathrm{N}$, which is the approximate sea-ice edge at the time of study. Color scales for height and latitude are given to the right of the upper and lower panels, respectively. Case study periods are given as blue lines along the lower time axes.

within, the base of clouds. In broken clouds, profiles were flown through the layer occupied by clouds.

\subsection{Air mass trajectories}

Three-dimensional, five-day backward air parcel trajectories (Fig. 2) were calculated using the Hybrid Single Particle Lagrangian Integrated Trajectory Model (HYSPLIT; Draxler and Rolph, 2011; Rolph, 2011). The trajectories were based on data from the Global Data Assimilation System of the US National Centers for Environmental Prediction. Vertical motion in the trajectory runs was calculated using the model vertical velocity fields. The receptor point above Oden was set at $0.5 \mathrm{~km}$ altitude.

\section{Case studies}

Using this sophisticated set of measurements and derived products, example case studies are used to demonstrate important ways in which stratiform, mixed-phase clouds at ASCOS interacted with the boundary layer structure, aerosol concentrations, and surface fluxes. In all cases, ground-based remote sensor and radiosonde measurements consistently indicated the same basic cloud structure, consisting of at least one layer of supercooled liquid water from which ice crystals formed and fell (e.g., Shupe et al., 2006). Cloud-driven dynamics created mixed layers that usually extended from the cloud top down below cloud base. Of particular interest here is the proximity of these mixed layers to the surface.

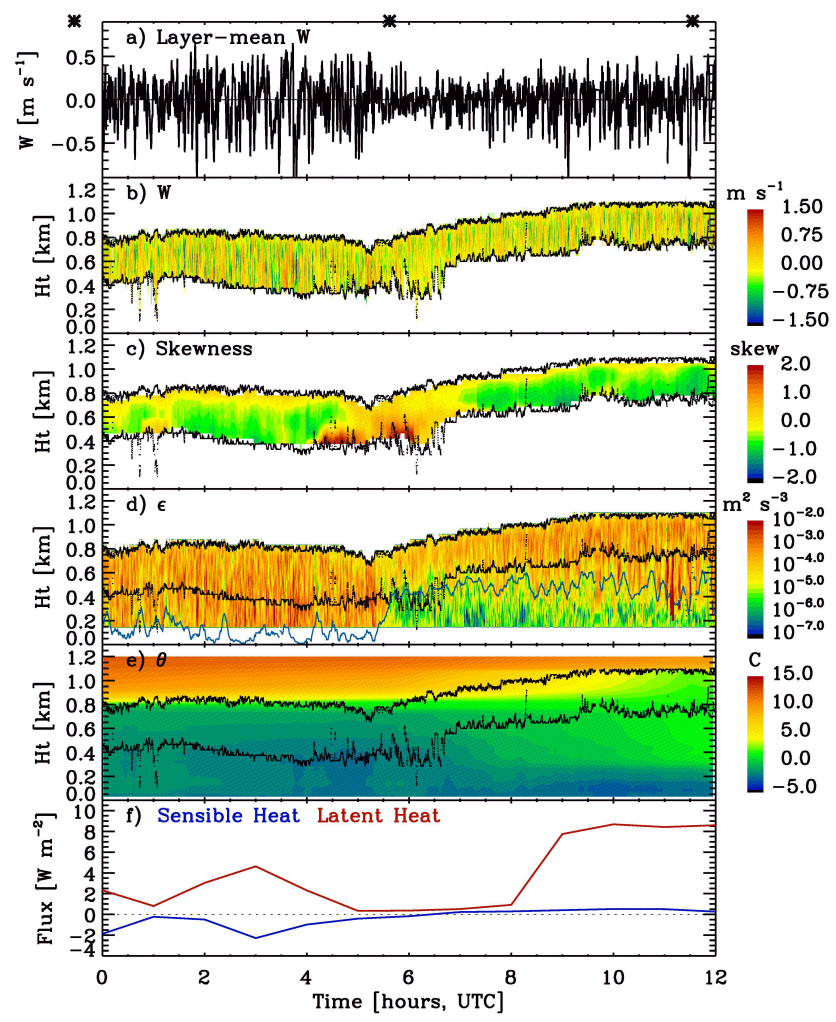

Fig. 3. Remote-sensor-derived cloud and atmosphere dynamical properties for 28 August 2008 (Case \#1), including (a) layer-mean vertical velocity, (b) vertical velocity within the liquid cloud layer, (c) skewness of vertical velocity over running $30 \mathrm{~min}$ windows, (d) turbulent dissipation rate, (e) potential temperature, and (f) surface turbulent sensible (blue) and latent (red) heat fluxes. Liquid cloud boundaries are given in black in the middle four panels, while the base of the cloud-driven mixed layer is given in blue in (d). Launch times for radiosoundings in Fig. 4 are given as black stars along the top axis.

Periods when the mixed layer extended down to the surfacebased boundary layer are referred to as coupled, while periods when the mixed layer was above the surface-based boundary layer are referred to as decoupled.

\subsection{Case \#1: 28 August 2008, 00:00-12:00 UTC}

During this period an extensive deck of stratiform clouds was observed by visible channels on the Moderate Resolution Imaging Spectroradiometer (MODIS) satellite (not shown) to be advecting south and west around a slow-moving highpressure center approaching Oden from the north. This case nicely illustrates a transition in the coupling state and boundary layer structure related to cloudiness. The transition at Oden started at about 05:00 (all times are in UTC) as the cloud layer lifted over the course of a few hours (Fig. 3). A weak, low-level jet observed by the wind profiler, possibly associated with a weak mesoscale front, formed below cloud base during this transition period (not shown). Additionally, 

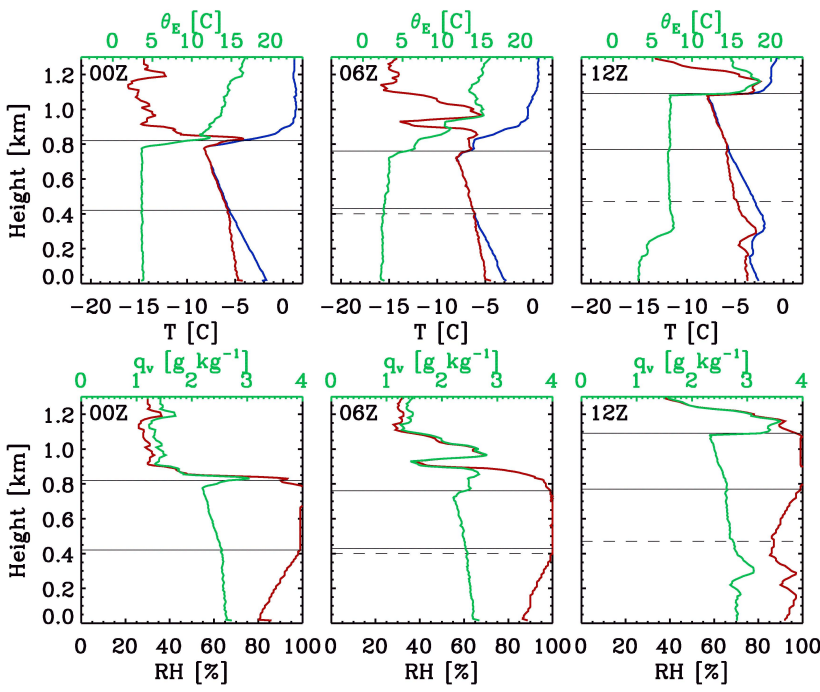

Fig. 4. Measurements from $0 \mathrm{Z}$ (left), $6 \mathrm{Z}$ (middle), and $12 \mathrm{Z}$ (right) soundings on 28 August 2008 (Case \#1). Panels in the top row contain dry bulb (blue) and dew point (red) temperatures referenced to the lower axis and equivalent potential temperature (green) referenced to the upper axis. Panels in the lower row contain the relative humidity (red) referenced to the lower axis and specific humidity (green) referenced to the upper axis. In each panel, liquid cloud boundaries are designated by horizontal solid lines, while the approximate base of the cloud-driven mixed layer is designated by a horizontal dashed line (and the mixed-layer base is assumed to be at the surface during the $0 \mathrm{Z}$ sounding). Soundings are launched about $30 \mathrm{~min}$ prior to the nominal sounding time.

back-trajectory model simulations suggest a subtle change in air mass origin. Five-day back trajectories for the $0.5 \mathrm{~km}$ height above Oden all descend as they approach (see Fig. 2), initially originating in the northern Canadian archipelago, but shifting towards ice-free regions in the Beaufort Sea at the time of transition.

Other measurements revealed a consistent view of this transition. The initial, radiosonde-measured $\theta_{E}$ profile (Fig. 4) was approximately constant from inversion base at $0.8 \mathrm{~km}$ down to the surface, indicating a layer of near-neutral, moist static stability that was well mixed. In other words, the cloud was coupled to the surface. Over the ensuing $12 \mathrm{~h}$, while near-surface $\theta_{E}$ remained relatively constant, $\theta_{E}$ in the elevated cloud-driven mixed layer warmed by $4{ }^{\circ} \mathrm{C}$. During this transition, the mixed-layer top slowly lifted to $1.1 \mathrm{~km}$, consistent with the transition in observed radar cloud top (Fig. 3). The 6Z sounding (05:35 launch time) showed stepwise transitions in $\theta_{E}$ near cloud top from the initial state towards the final state. Importantly, this warming aloft helped create a near-surface, statically stable layer in the lowest $0.3 \mathrm{~km}$ that decoupled the cloud-driven mixed layer from the surface. The $60-\mathrm{GHz}$ radiometer-derived $\theta$ shows this same transition with higher temporal resolution (Fig. 3e).
Humidity measurements (Fig. 4) suggest that moisture advection above cloud top contributed to this transition. All soundings showed a cloud-top-specific humidity ( $q_{v}$, or water vapor mixing ratio) inversion that supported condensed cloud water within the stable temperature inversion. The mixed-layer $q_{v}$ just below cloud base provides an estimate of the mixed-layer total water mixing ratio $\left(q_{\mathrm{t}}\right)$, which is assumed to be approximately constant throughout the mixed layer (where the decrease in $q_{\mathrm{v}}$ within the cloud is due to condensation). The $0 \mathrm{Z}$ sounding suggests a mixed-layer $q_{\mathrm{t}}$ of $2.5 \mathrm{~g} \mathrm{~kg}^{-1}$, implying a small total water inversion at cloud top below a relatively dry free troposphere. During the transition, an additional moist layer was observed at $1 \mathrm{~km}$, and by $12 \mathrm{Z}$ a broader, and stronger, total water inversion existed at $1.1 \mathrm{~km}$. Specific humidity also increased below the clouddriven mixed layer at this time.

To first order, there are two regimes in the derived $\varepsilon$ field (Fig. 3d): high values associated with active turbulent mixing and lower values where turbulence is limited. During the first $5.5 \mathrm{~h}$ of the case, high $\varepsilon$ extended through the cloud layer and down to the surface, consistent with active mixing throughout this layer. However, coincident with the cloudatmosphere transition suggested by other measurements, the $\varepsilon$ structure changed significantly. After this time, high $\varepsilon$ extended only a few hundred meters below cloud base with a significant decrease below about $0.3-0.5 \mathrm{~km}$. This interface is the base of the cloud-driven mixed layer, consistent with the $12 \mathrm{Z}$ sounding.

Cloud-layer vertical motions weakened for a couple hours at 05:00 but increased again thereafter (Fig. 3a). Vertical velocity skewness (Fig. 3c) was somewhat negative within the cloud layer, indicating that the $w$ distribution was characterized by relatively stronger, narrower downdrafts with weaker, broader updrafts. This structure is consistent with the forcing for these motions coming from above (e.g., Hogan et al., 2009), in this case being primarily driven by cloud-top radiative cooling. Cloud LWPs remained between 50 and $120 \mathrm{~g} \mathrm{~m}^{-2}$ for this whole case, except for a brief decrease during the transition (not shown). For three hours during the transition the skewness became more positive, perhaps related to mesoscale circulations (i.e., weak low-level jet or weak frontal lifting) near the leading edge of this transition.

For almost the entire case there was a distinct increase in $w$ skewness near cloud top that provides insight into important cloud-top processes related to moisture inversions. Radiative cooling destabilizes cloud parcels below the temperature inversion base leading to buoyancy-driven shallow overturning (i.e., mixed-layer formation), with a negative skewness. However, this same destabilization does not occur when cloud water that resides within the temperature inversion radiatively cools. Rather, it is expected that cooling in this relatively moist region directly forces condensation (Curry et al., 1988; Solomon et al., 2011). As a result, these skewness values suggest that the $w$ distribution for these cloud parcels within the inversion was unique relative to those that 

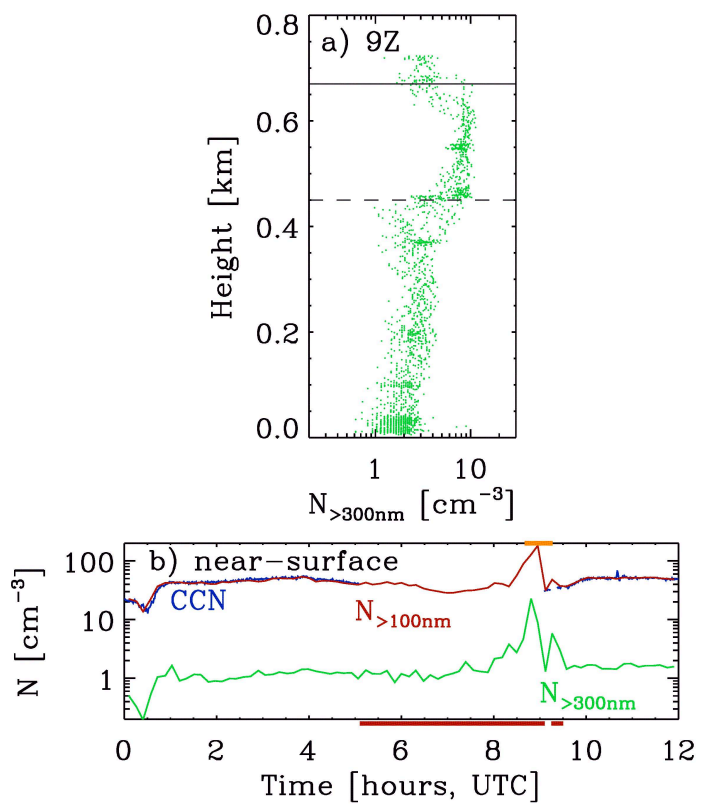

Fig. 5. Near-surface and helicopter aerosol measurements on $28 \mathrm{Au}$ gust 2008 (Case \#1), including (a) helicopter profile of aerosol concentration for particles larger than $300 \mathrm{~nm}$ taken at about 9Z, and (b) concentrations of CCN (blue), aerosols larger than 100nm (red) and aerosols larger than $300 \mathrm{~nm}$ (green) measured onboard Oden. In (a), the solid and dashed lines are the cloud base and mixed-layer base heights determined by remote sensors at the time, respectively. Red bars on the lower axis of (b) indicate questionable data due to contamination, while the orange bar on the top axis shows the time of the helicopter profile.

resided below the temperature inversion within the clouddriven mixed layer.

Surface turbulent heat fluxes were small (Fig. 3f) and likely had little impact on cloud-driven mixed-layer dynamics. The latent heat flux was positive but variable. The sensible heat flux appears to have responded to changes in the cloud-surface coupling state rather than force them. Prior to the transition, the surface was warmed as the cloud-driven mixed layer drove heat down towards the surface. After the transition, the sensible heat flux provided a small amount of heating to the now colder near-surface atmosphere.

Near-surface aerosol measurements did not change appreciably as a result of the transition in the cloud-surface coupling state (Fig. 5). From 05:00 to 09:30 the near-surface measurements cannot be fully trusted due to potential contamination, although ship pollution mainly affects particle number concentrations at sizes smaller than $300 \mathrm{~nm}$. Qualityassured samples before and after this time showed nearly identical aerosol and CCN concentrations. A helicopter profile at 09:00 indicated a near-surface $N_{>300}$ that was in good agreement with the Oden-based aerosol measurements of the same size range. $N_{>300}$ increased slightly with height until approximately $0.45 \mathrm{~km}$, which was the cloud-driven

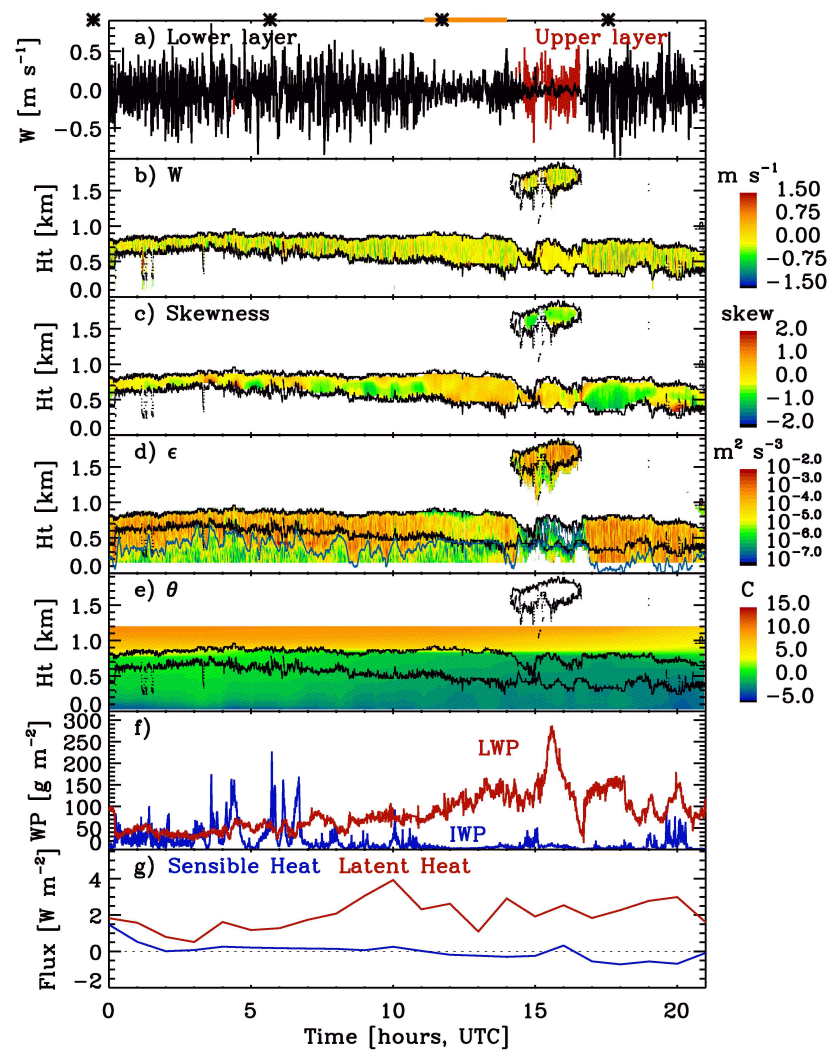

Fig. 6. Remote-sensor-derived cloud and atmosphere dynamical properties for 29 August 2008 (Case \#2), including (a) layer-mean vertical velocity, (b) vertical velocity within the liquid cloud layers, (c) skewness of vertical velocity over running $30 \mathrm{~min}$ windows, (d) turbulent dissipation rate, (e) potential temperature, (f) LWP (red) and IWP (blue) for clouds below $2 \mathrm{~km}$, and (g) surface turbulent sensible (blue) and latent (red) heat fluxes. Liquid cloud boundaries are given in black in (b-e), while the base of the cloud-driven mixed layer is given in blue in (d). The black line in panel a is for the lower cloud layer, while the red line is for the upper altocumulus layer. The orange bar along the top axis shows the time period when a second upper cloud had descended below $5 \mathrm{~km}$. Black stars on the top axes designate the launch time for radiosondes shown in Fig. 7.

mixed-layer base identified using remote sensor measurements. From that height up to cloud base at $0.66 \mathrm{~km}, N_{>300}$ was constant and somewhat higher; it then decreased above that height as many particles activated into cloud drops that were not sampled through the aerosol inlet. No information is available on particle concentrations above cloud top, but it is clear that the highest particle concentrations at this time were associated with the decoupled, mixed layer as opposed to the near-surface boundary layer.

\subsection{Case \#2: 29 August 2008, 00:00-21:00 UTC}

The second case encompassed a transition from the decoupled cloud state described at the end of Case \#1 back towards a cloud-surface coupled state, with an added complication 

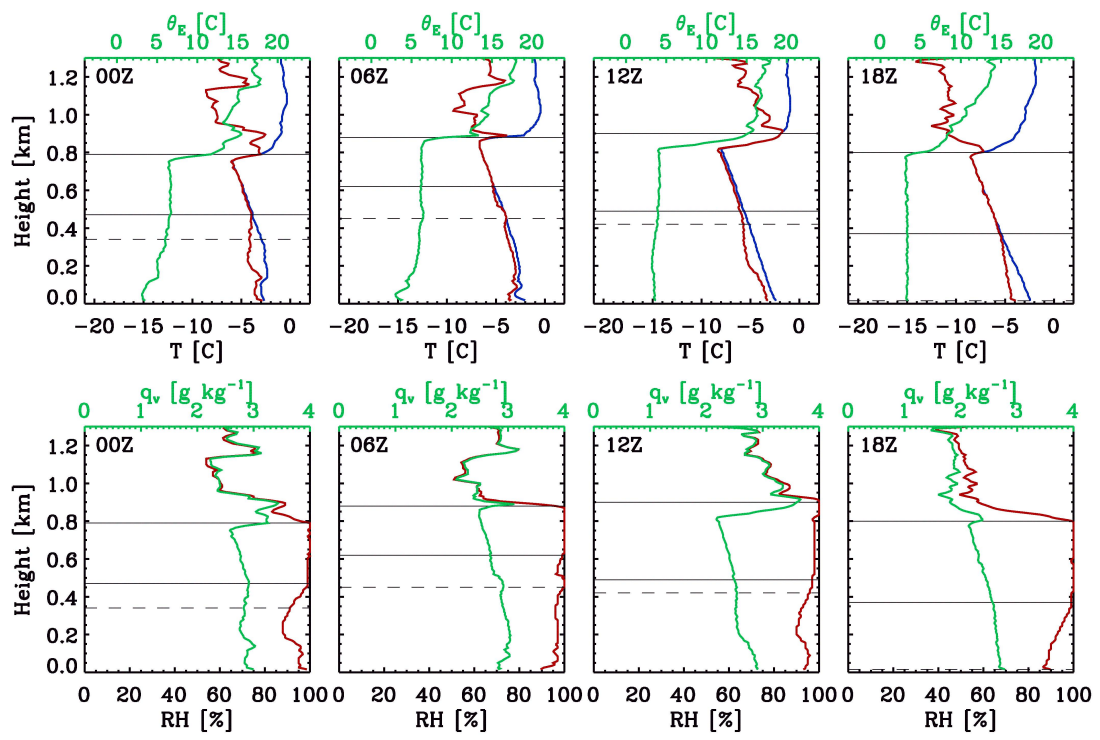

Fig. 7. As in Fig. 4, but for 0Z, 6Z, 12Z, and 18Z soundings (moving left to right) on 29 August 2008 (Case \#2).

of multiple cloud layers influencing the low-level cloud processes. As with the prior case, a persistent, low-level, mixedphase stratocumulus cloud occurred above Oden (Fig. 6), being initially stationary under a weakening, stalled highpressure center, then in time moving slowly towards the eastnortheast. Back-trajectory analyses indicate that the cloudlevel air mass descended slowly (Fig. 2) as it advected from ice-free regions of the eastern Beaufort Sea out over the central Arctic ice pack towards Oden over 3-4 days. Two types of upper layer clouds were also observed: a mixedphase altocumulus at $\sim 1.5 \mathrm{~km}$ from 14:00 to 17:00 and upper level, cirriform clouds during much of the case (not shown in Fig. 6). The remote sensor suite indicated that these cirriform clouds were primarily composed of ice and remained above $5 \mathrm{~km}$, except for the period of 11:00-14:00 when the upper cloud base descended below $5 \mathrm{~km}$ and the cloud became substantially thicker.

Many of the same signatures described for the previous case are again useful for this case. Radiosonde $\theta_{E}$ profiles (Fig. 7) showed an initially decoupled, cloud-driven mixed layer sitting atop a stable layer at $\sim 0.4 \mathrm{~km}$. Near-surface $\theta_{E}$ remained steady over time, while the mixed layer cooled under increasing, cloud-level winds from the northwest. By 12:00 the surface-based mixed layer had deepened, and by 18:00 had joined with the cooling, cloud-driven mixed layer, resulting in cloud-surface coupling. Moisture near and above cloud top was relatively high in the initial soundings, but decreased by 18:00. Cloud-top $q_{v}$ inversions existed throughout, with a very strong moisture inversion in the $12 \mathrm{Z}$ sounding. During the entire case, the cloud top protruded into the temperature inversion at about -6 to $-8^{\circ} \mathrm{C}$, again accompanied by a cloud-top increase in $w$ skewness (Fig. 6c), and from about 05:00 to the end of the case the cloud top and temperature inversion base both descended slowly.

The $\varepsilon$ and $\theta$ fields (Fig. 6d, e) both showed clear transitions from an elevated cloud-driven mixed layer prior to about 12:00 towards a mixed layer extending from cloud to surface thereafter (neglecting for the moment the period of multiple cloud layers from 11:00 to 17:00). Interestingly, the $\varepsilon$ profiles showed what appeared to be a turbulent layer growing in depth from the surface upward at 13:00-15:00, consistent with the $12 \mathrm{Z}$ sounding. However, surface turbulent heat fluxes were again weak (Fig. 6g). The trend in sensible heat flux was similar to Case \#1, with slightly positive fluxes under a decoupled situation and a transition towards small negative fluxes as the cloud-driven mixed layer began to drive heat towards the surface.

An additional aspect of this case is the influence that upper-level clouds had on this low-level stratocumulus. Between 14:00 and 17:00, the turbulent motions were greatly diminished (Fig. 6a, b, d) as the optically opaque altocumulus at $1.5 \mathrm{~km}$ inhibited the stratocumulus cloud-top radiative cooling. Since the altocumulus cloud was able to effectively cool to space, $\varepsilon$ values in that layer were similar to those in the unshaded stratocumulus. Subtle turbulence changes were also seen in the stratocumulus starting at about 11:00, coincident with the lowering and deepening of the cirrus cloud above $4 \mathrm{~km}$ (not shown). These highest clouds were apparently not as optically thick as the altocumulus, and thus had a smaller impact. While the $w$ skewness was typically negative in the stratocumulus, there was a marked transition towards a more neutral or positive skewness when upper clouds were present, as the cloud-top forcing of in-cloud turbulent motions was diminished. 
The cloud properties themselves responded to changes in coupling state, the presence of multiple cloud layers, and/or the air mass transitions that accompany them. A general decrease in cloud top from 05:00 to the end of the case was concurrent with drying throughout the lower troposphere. At the same time, and in spite of the drying, the cloud thickness increased as the stratocumulus transitioned towards the coupled state after 12:00, with a commensurate increase in LWP (Fig. 6f). On the other hand, cloud ice production decreased with the transition to the coupled state. LWP was well correlated with the total liquid cloud thickness throughout. There was also an unexplained feature from 03:00 to 07:00 where periods of enhanced ice production coincided with skewness values that were more positive, indicating some relation between changes in air motions and ice processes at this time.

There was a substantial LWP peak when the altocumulus layer was present. While this set of remote sensors did not have sufficient information to distribute the LWP between multiple layers, this increase was presumably due to liquid water present in both layers. Immediately after the altocumulus advected away, the total LWP plummeted to $20 \mathrm{~g} \mathrm{~m}^{-2}$, suggesting the approximate LWP of the shaded stratocumulus. This response was likely due to the fact that the altocumulus was advecting faster than the stratocumulus and continually exposing new portions of the diminished, lower-level cloud. Within $30 \mathrm{~min}$, this newly exposed cloud again cooled effectively to space, cloud processes became active, and the LWP recovered.

Aerosol measurements both near the surface and aloft suggested that aerosol concentrations were again largest within the cloud-driven mixed layer (Fig. 8). At 09:00, the nearsurface $N_{>100}$ was low, similar to the CCN concentration, while $N_{>300}$ was even lower. Around 10:00-11:00 all concentrations started to increase, with a net $\mathrm{CCN}$ increase from 10 to $85 \mathrm{~cm}^{-3}$ by 21:00. Three helicopter profiles nicely captured the evolution of vertical aerosol structure. The first of these at 09:00 showed near-surface $N_{>300}$ below $1 \mathrm{~cm}^{-3}$ and an increase with elevation up to the base of the cloud-driven mixed layer at $0.3 \mathrm{~km}$. Above this level, the concentration was constant up to cloud base near $0.55 \mathrm{~km}$, and then decreased aloft due to cloud droplet activation. The 13:30 profile, after the cloud-surface coupling process had started, was significantly different. Low-level $N_{>300}$ had increased, commensurate with the observed near-surface increase, and there was a slight increase with elevation up to the cloud base at $0.4 \mathrm{~km}$. By 19:00, near-surface $N_{>300}$ had again increased and the concentration was approximately constant from the surface up to cloud base above $0.3 \mathrm{~km}$.

\subsection{Case \#3: 25 August 2008, 00:00-11:30 UTC}

The final case study did not involve a distinct transition in cloud-surface coupling state, although the coupling appeared to be intermittent. In this case, a mixed-phase stratocumulus below $0.7 \mathrm{~km}$ was present throughout, while a
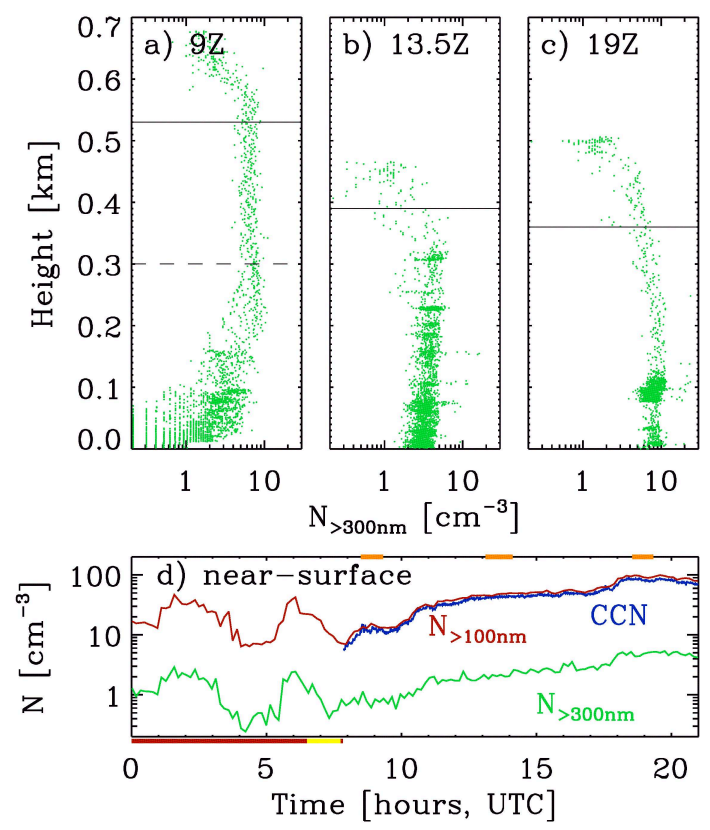

Fig. 8. Near-surface and helicopter aerosol measurements on $29 \mathrm{Au}-$ gust 2008 (Case \#2), including helicopter profiles of aerosol concentration for particles larger than 300nm taken at about (a) 9Z, (b) 13.5Z, and (c) 19Z, and (d) concentrations of CCN (blue), aerosols larger than 100nm (red) and aerosols larger than $300 \mathrm{~nm}$ (green) measured onboard Oden. In (a-c), the solid and dashed lines are the cloud base and mixed-layer base heights determined by remote sensors at the time, respectively. Red bars on the lower axis of (d) indicate questionable data due to contamination (yellow bars may also be questionable due to temporal proximity), while the orange bars on the top axis show the times of the helicopter profiles.

mid-level cloud shaded the stratocumulus for the first couple hours (Fig. 9). Satellite and wind profiler observations (not shown) both showed the mid-level cloud moving northnortheast, while the underlying stratocumulus advected westward. Back-trajectory analyses indicate that the $0.5 \mathrm{~km}$ flow at Oden passed over the sea-ice edge in the Fram Strait about one day prior to the case. In contrast to other cases, this air mass remained at or below $0.5 \mathrm{~km}$ for the prior couple of days (Fig. 2).

Initially, with the geometrically thin yet optically thick mid-level cloud overhead, the low-level stratocumulus had diminishing $\varepsilon$ with height (Fig. 9c). Strong narrow updrafts periodically emanated from the surface (Fig. 9a), leading to positive near-surface $w$ skewness. At this time there was a shallow surface-based mixed layer indicated by the $0 \mathrm{Z} \theta_{E}$ sounding (Fig. 10) and retrieved $\theta$ field (Fig. 9d). Surface sensible heat fluxes were near neutral to weakly positive at this time, and thus might have contributed to the forcing for this mixed layer. Near-surface wind shear (not shown) associated with a weak low-level jet likely also contributed to mechanical mixing. 


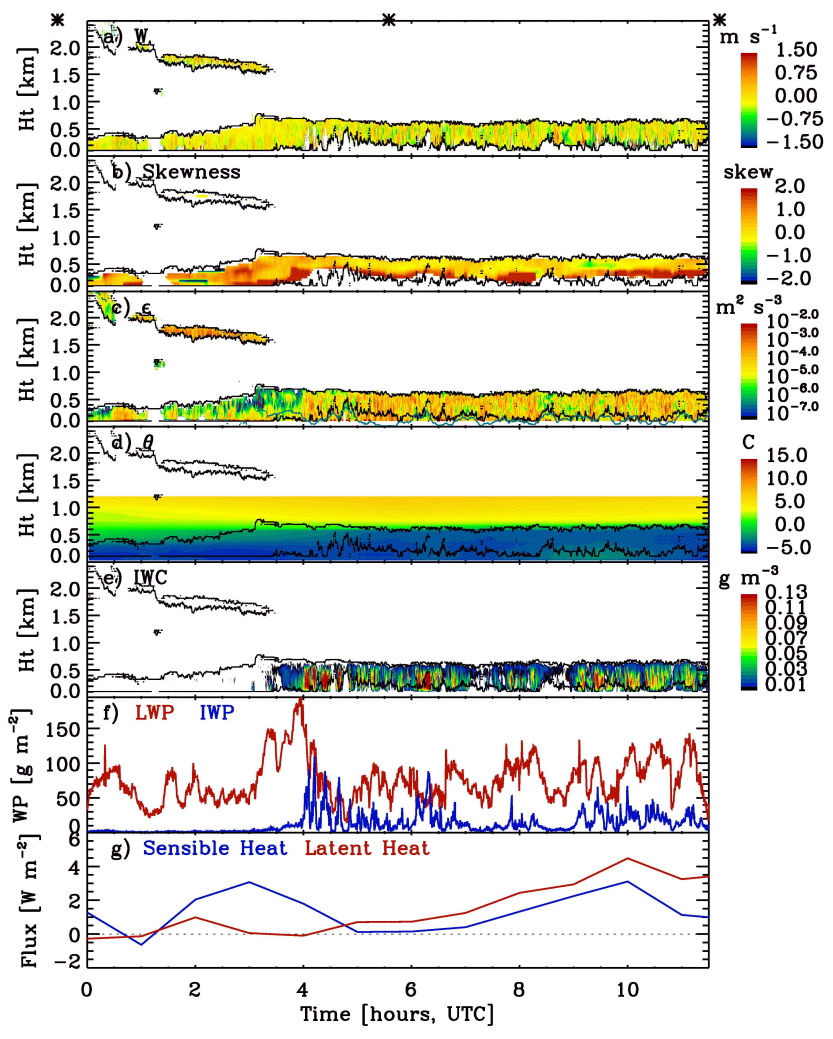

Fig. 9. Remote-sensor-derived cloud and atmosphere dynamical properties for 25 August 2008 (Case \#3), including (a) vertical velocity within the liquid cloud layer, (b) skewness of vertical velocity over running $30 \mathrm{~min}$ windows, (c) turbulent dissipation rate, (d) potential temperature, (e) IWC, (f) LWP (red) and IWP (blue), and (g) surface turbulent sensible (blue) and latent (red) heat fluxes. Liquid cloud boundaries are given in black in the upper five panels, while the base of the cloud-driven mixed layer is given in blue in (c). Launch times for the radiosondes in Fig. 10 are given as stars across the top axis.

At 03:30 the mid-level cloud advected away, eliciting a significant response in the stratocumulus layer (Fig. 9). About 30 min after being exposed, turbulence increased near cloud top due to more effective cooling to space. Cloud-top $w$ skewness became more neutral in time, consistent with the increased contribution of radiative cooling towards forcing vertical motions. An increased depth of mixing, extending from the surface to cloud top, was apparent in the $\theta$ field (Fig. 9d) and the 6Z radiosonde (Fig. 10). Soundings also showed drying aloft after the mid-level cloud left and a slightly decreased mixed-layer $q_{\mathrm{t}}$ in time. Only after the midlevel cloud was gone did the radiosoundings indicate cloud top protruding into the temperature inversion, suggesting that strong radiative cooling was needed to promote this process.

LWP was typically within the range of $30-120 \mathrm{~g} \mathrm{~m}^{-2}$ for the duration of this case. For the first few hours, some portion of the LWP was associated with the mid-level cloud, while the lower stratocumulus likely had diminished liquid
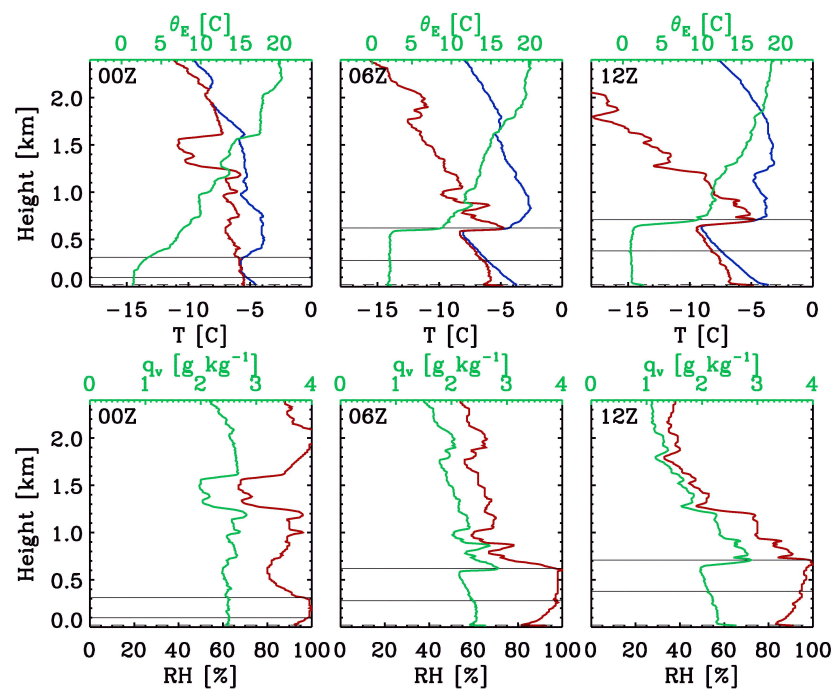

Fig. 10. As in Fig. 4, but for $0 \mathrm{Z}$ (left), $6 \mathrm{Z}$ (middle), and $12 \mathrm{Z}$ (right) soundings on 25 August 2008 (Case \#3).

water amounts. Immediately after the stratocumulus became unshaded, a burst of liquid was produced as cloud processes became more active, with peak LWP reaching $190 \mathrm{~g} \mathrm{~m}^{-2}$ before settling back down to the typical range as ice production increased. After 04:00, cloud base height was variable, with LWP increases occurring when the cloud base descended and cloud layer thickened.

Near-surface aerosol concentrations demonstrated a unique correspondence with cloud liquid water in this case (Fig. 11). First, there existed a strong consistency between CCN concentration and $N_{>100}$. An increase of CCN occurred within the first hour, with a slow decline until 03:00. Between 03:00 and 05:00 the CCN concentration increased from 10 up to 50 and then decreased back to $15 \mathrm{~cm}^{-3}$ in coordination with the pulse of liquid water production. Shortly thereafter $\mathrm{CCN}$ measurements were no longer available, but $N_{>100}$ continued to increase and decrease in coordination with broad increases and decreases in LWP (with a correlation coefficient of 0.6 when LWP was averaged to the aerosol measurement times). Increases in both aerosol concentrations and LWP also coincided with a deepening of the cloud layer, a descent of cloud base, and a decrease in near-surface visibility. A helicopter $N_{>300}$ profile made three hours prior to this case and prior to the low-cloud formation (Fig. 11a) showed a large increase above $0.5 \mathrm{~km}$ relative to near the surface. During the 09:00 flight, peak near-surface $N_{>300}$ was nearly as large as the upper-level concentrations present before. While it was difficult to resolve the exact atmospheric structure in the lowest $0.15 \mathrm{~km}$, the variability and vertical structure of these observations are consistent with aerosol concentrations being larger aloft than near the surface, and cloud-driven vertical mixing periodically transporting some of these aerosols down towards the surface. In other words, the cloud-driven 

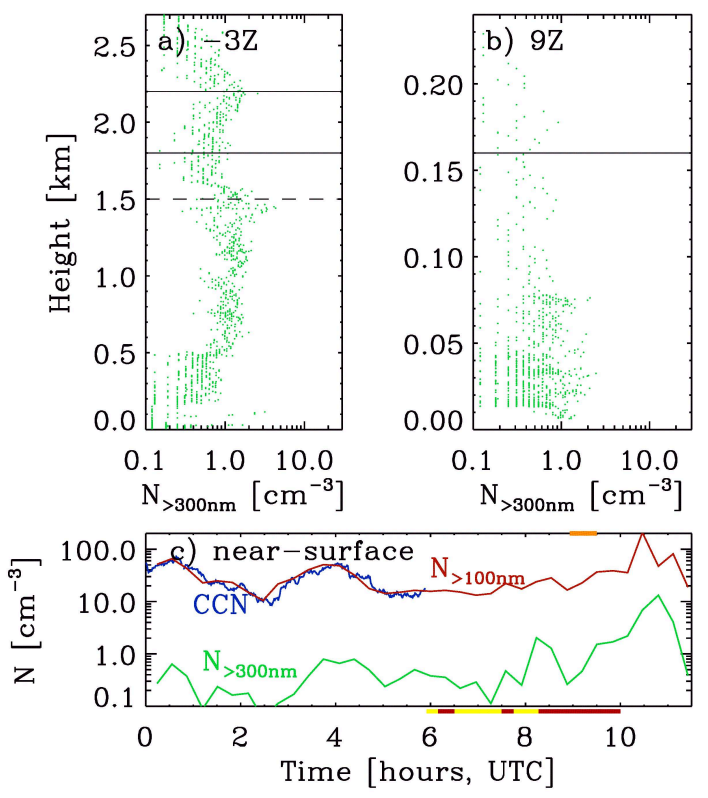

Fig. 11. Near-surface and helicopter aerosol measurements on 25 August 2008 (Case \#3), including helicopter profiles of aerosol concentration for particles larger than $300 \mathrm{~nm}$ taken (a) about $3 \mathrm{~h}$ prior to $0 \mathrm{Z}$ and (b) $9 \mathrm{z}$, and (c) concentrations of CCN (blue), aerosols larger than $100 \mathrm{~nm}$ (red) and aerosols larger than $300 \mathrm{~nm}$ (green) measured onboard Oden. In (a-b), the solid and dashed lines are the cloud boundaries and mixed-layer base heights determined by remote sensors at the time, respectively. Red bars on the lower axis of (c) indicate questionable data due to contamination (yellow bars may also be questionable due to temporal proximity), while the orange bar on the top axis shows the time of the second helicopter profile. Note the different vertical scales for (a) and (b) .

mixed layer was intermittently coupled to the surface boundary layer (when LWP was high and cloud base was low), and weakly decoupled at other times.

Another interesting aspect of this case was that cloud ice production was minimal when the stratocumulus was shaded but ramped up significantly as cloud-top turbulence increased (Fig. 9e, f). Between the $0 \mathrm{Z}$ and $6 \mathrm{Z}$ soundings (Fig. 10) cloud-top temperature only cooled from -6 to $-8^{\circ} \mathrm{C}$, a difference that was likely not sufficient to explain the dramatic change in ice production. Unfortunately, little information on local ice nuclei (IN), which are needed for ice particle nucleation at these temperatures, is available. Potential explanations for this behavior include (1) IN being brought into the system via cloud-top entrainment (Fridlind et al., 2012), which increases as cloud-top turbulence increases; (2) more active cloud motions leading to the formation of more large liquid droplets that are preferentially active in some freezing mechanisms (Lance et al., 2011); or (3) more active cloud motions begetting higher peak supersaturations that support enhanced nucleation via certain mechanisms. Moderate correlation between LWP and IWP in this case could support any of these possibilities. Further, the suggestion of higher aerosol concentrations aloft might support hypothesis $\# 1$, although IN concentrations aloft are unknown. Thus, at present, there is insufficient information to further constrain this phenomenon.

\section{Statistical description of ASCOS stratocumulus period}

The principles used to characterize the individual case studies were applied to the week-long, ASCOS stratocumulus phase from 24 to 31 August (Fig. 12) in order to explore the cloud-surface coupling state and its relationship to cloud properties and atmospheric mixing in a more general way. Periods having at least intermittent cloud-surface coupling are characterized by layers with small and/or negative $\theta$ gradients from the surface up to cloud layer and mixed-layer bases that periodically extend down to the surface (green hatched periods in Fig. 12). Periods that show consistent cloud-surface decoupling generally have layers of positive $\theta$ gradient and a mixed-layer base at some height between cloud and surface (red hatched periods in Fig. 12). None of the specified time periods is homogeneous and there is some crossover in characteristics between these states. To provide a general characterization of the observed stratocumulus clouds, and to contrast coupled versus decoupled subsets, statistics are examined for all periods having a low-level, liquid-containing cloud with top between 0.5 and $1.5 \mathrm{~km}$ that was not shaded by an optically thick upper cloud layer (black line on top axes in Fig. 12). Moreover, cases are only considered where hydrometeors are present from cloud level down to the surface, or to below the identified mixed-layer base, to ensure that the mixed-layer base can be determined using the methods presented here. Of these time periods, the mixed-layer base is identified above $0.15 \mathrm{~km}$, representing a decoupled state, $75 \%$ of the time.

First, considering the full time series in Fig. 12, it is apparent that cloud-surface coupled time periods are typically associated with lower clouds, while decoupled scenes are most often associated with clouds that are lifted further off the surface relative to surrounding time periods. This difference is borne out by examining probability distribution functions (PDFs) distinguished by coupling state (Fig. 13). In addition to being higher, decoupled clouds are often thinner and more frequently contain smaller LWP and IWP relative to surfacecoupled clouds. The distribution of $w$ is similar in all cases, with extreme values reaching $\pm 1 \mathrm{~m} \mathrm{~s}^{-1}$. However, $w$ skewness is most often negative in decoupled cases but more neutral in coupled cases, including a tail towards highly positive values that are related to stronger forcing from below. Distributions of $\varepsilon$ are relatively more skewed towards low values in decoupled cases. However, when only considering $\varepsilon$ within the mixed layer, it is more often larger in decoupled cases. For all parameters, the total distribution is closer to that of 

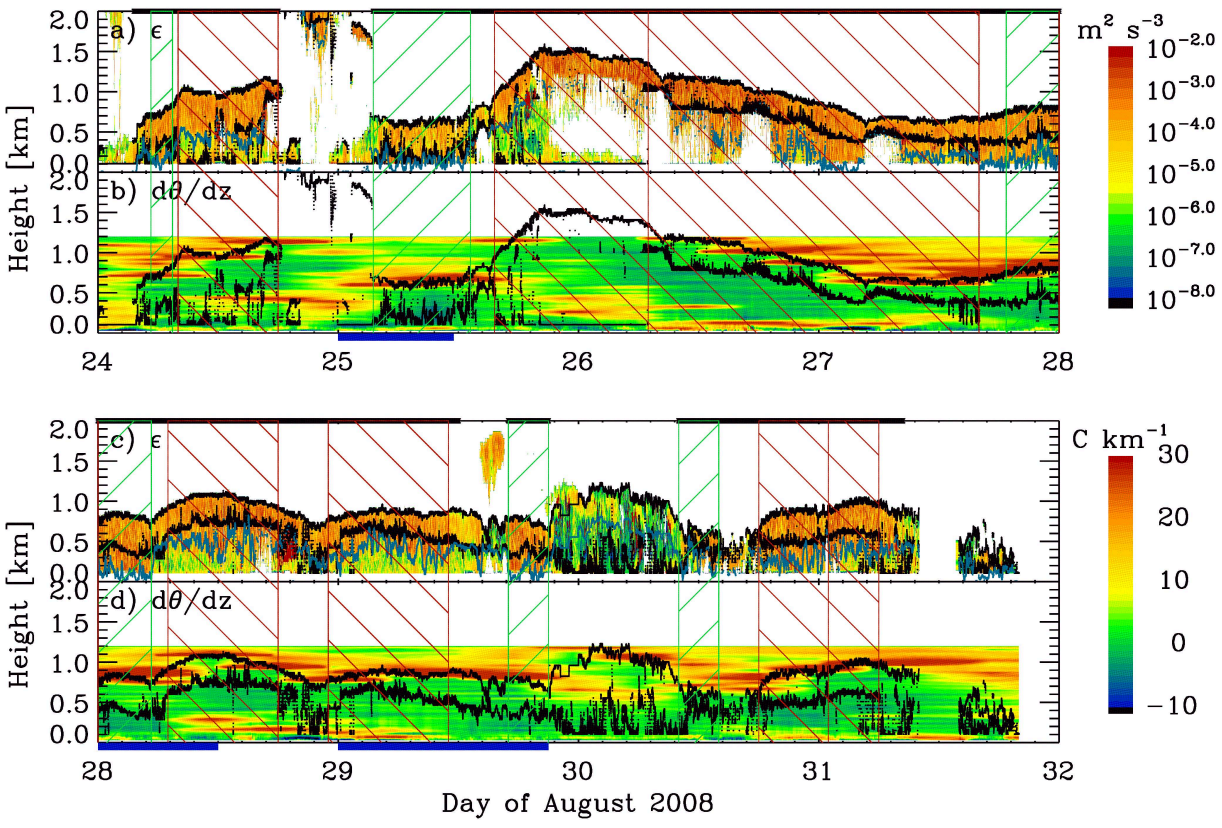

Fig. 12. Time-height contour plots of (upper) turbulent dissipation rate and (lower) vertical gradient of potential temperature for the "stratocumulus" time period of ASCOS. Two different 4-day periods are plotted. Cloud boundaries are given in black, while the base of the cloud-driven mixed layer is given in blue in the dissipation rate panels. Periods where the mixed layer is identified as being predominantly coupled (green) and decoupled (red) from the surface are noted with cross hatches. All time periods included in the statistical characterization in Sect. 4 are noted with the thick black bars across the top axes. Case study periods are given as blue lines along the lower time axes.
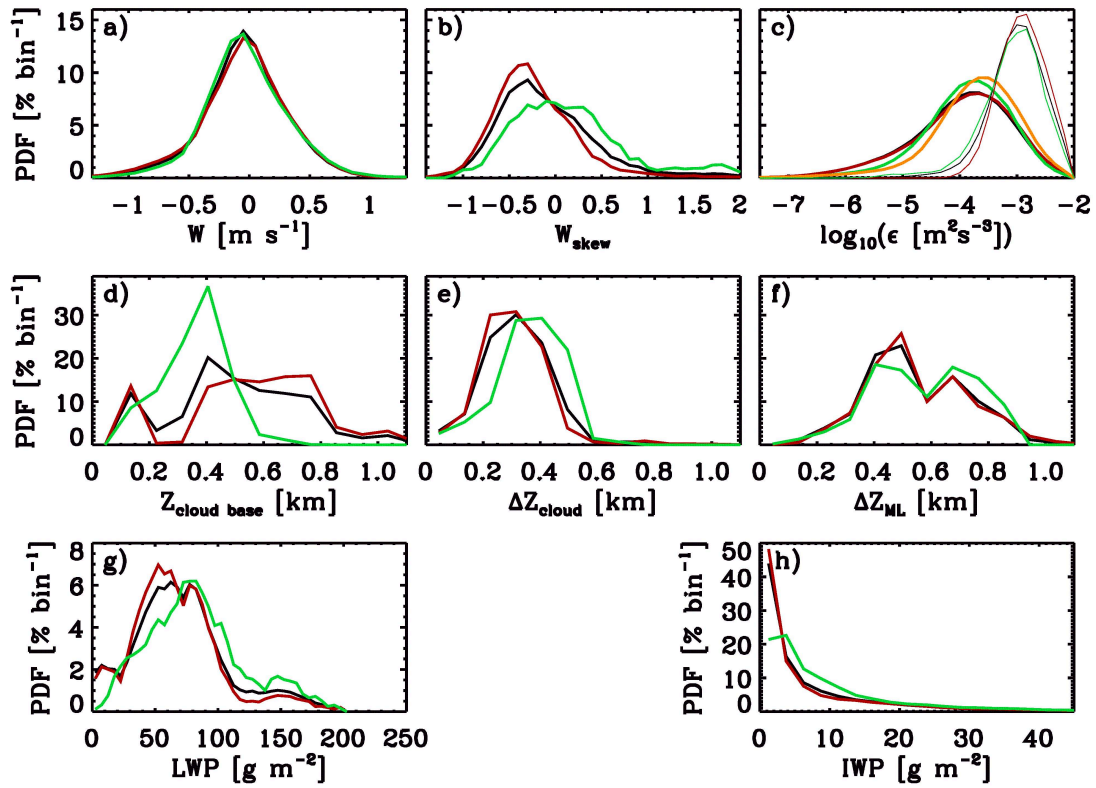

Fig. 13. Probability distribution functions of (a) vertical velocity, (b) vertical velocity skewness, (c) turbulent dissipation rate, (d) cloud base height, (e) cloud thickness, (f) mixed-layer thickness, (g) LWP, and (h) IWP. In all panels, the black curve is representative of all data noted by the thick black bars at the top of Fig. 12, red curves are for predominantly decoupled time periods noted with red cross hatches in Fig. 12, and the green curves are for intermittently coupled time periods noted with green cross hatches in Fig. 12. Additionally, (c) includes the PDF of $\varepsilon$ for predominantly decoupled time periods but only within the mixed layer (orange), and the thin curves represent the PDFs of layer-maximum $\varepsilon$. 

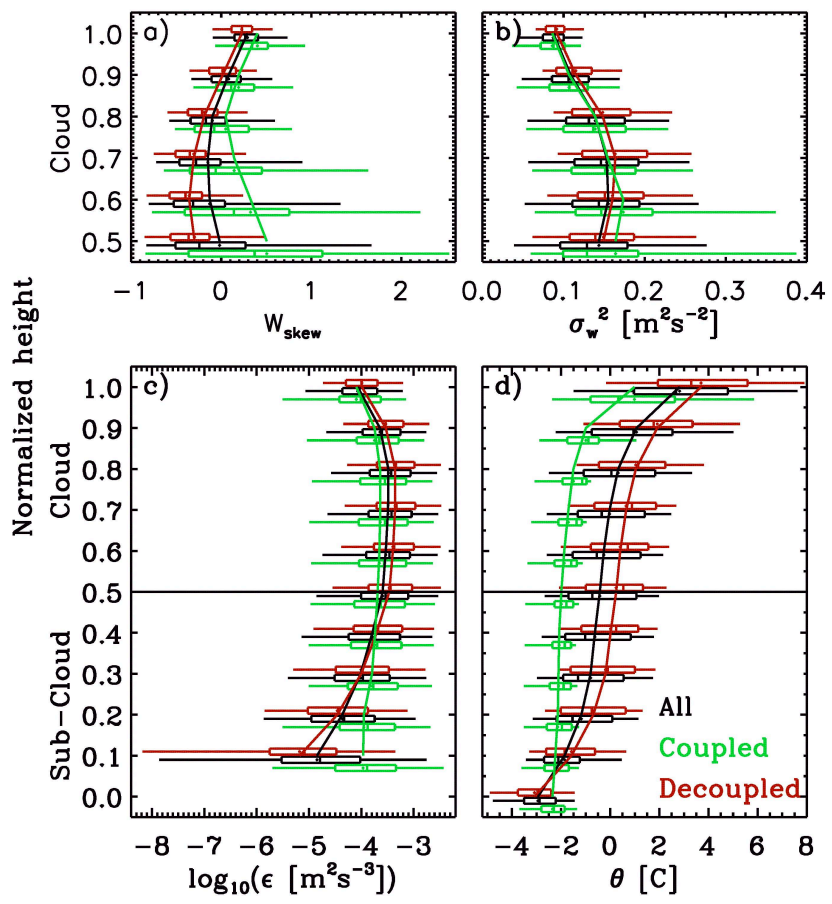

Fig. 14. Normalized statistical profiles of (a) vertical velocity skewness, (b) vertical velocity variance, (c) turbulent dissipation rate, and (d) 60-GHz radiometer-derived potential temperature. Black curves represent all data noted by the thick black lines at the top of Fig. 12, while the red and green curves are for the predominantly decoupled and intermittently coupled time periods noted in Fig. 12, respectively. Normalization is done relative to the cloud top (1.0), cloud base (0.5), and surface (0.0) in steps of 0.1 . At each normalized height level, box-and-whisker diagrams show the 5th, 25th, 50th, 75th, and 95th percentiles, while the continuous vertical curves represent the mean values. Statistics are computed at the same normalized heights for all data subsets, but are visualized at slightly different heights to facilitate comparisons. Since vertical velocity can only be determined within cloud layers, (a) and (b) only show normalized height ranges within cloud.

decoupled clouds, as these occurred three times as often as coupled clouds during the ASCOS stratocumulus period.

Normalized vertical profiles (Fig. 14) highlight some of these points in more detail and reveal how the parameters interact vertically. The gradient of $\theta$ is used to classify coupled versus decoupled conditions and therefore $\theta$ profiles show striking differences for these two subsets of data. Coupled cases have a semi-constant profile from just below cloud top down to the surface, consistent with this full layer being well mixed. Recall that $\theta$ will increase slightly when condensation occurs in a cloud layer. Decoupled cases show a similar, well-mixed profile separated vertically from the surface by a stable layer. In all cases, near-surface $\theta$ remains between -2 and $-3.5^{\circ} \mathrm{C}$, consistent with near-surface temperatures at this time (Sedlar et al., 2011), due in part to the steadying effect of the surface sea-ice and ocean water mixture. How- ever, decoupled, cloud-driven mixed layers are, on average, $\sim 2-3{ }^{\circ} \mathrm{C}$ warmer than coupled mixed layers and exhibit more variability in part due to a larger sample size. The warmer temperatures aloft in decoupled states suggest that these elevated mixed layers did not at any point upstream couple to, or equilibrate with, the cooler sea ice-ocean surface below. For either coupling state, $\theta$ increases near cloud top as does its variability. This behavior shows that in many cases, although not all, the cloud top extends into the temperature inversion (e.g., Sedlar et al., 2012).

Profiles of $\varepsilon$ (Fig. 14c) offer a consistent picture. Turbulence increases moving downward from the normalized cloud top, reaching relatively steady values through the lower part of the cloud. This transition towards higher $\varepsilon$ occurs over the same depth at which $\theta$ profiles show influence from the temperature inversion, implying a diminished $\varepsilon$ in clouds residing within the inversion. In the cloud layer, $\varepsilon$ is slightly larger in decoupled relative to coupled cases (Figs. 13c, 14c), perhaps due to the absence of dissipative interactions with the surface. Moving below cloud base, $\varepsilon$ decreases in decoupled cases but remains high for coupled cases, showing a clear relationship between well-mixed $\theta$ layers and high $\varepsilon$.

Profiles of $w$-related parameters are only available within the liquid cloud layer, but not below cloud base. Vertical velocity variance (Fig. 14b) is smallest near cloud top and at a maximum in the lower cloud, often lower for coupled cases versus decoupled cases. This profile shape is consistent with a typical eddy structure that extends from cloud to below cloud. Near cloud top (and mixed-layer base), eddy vertical motions naturally become smaller and less variable, while they are at a maximum in the middle of the eddies, which corresponds to a height that is typically in the lower part of the cloud.

Vertical velocity skewness (Fig. 14a) shows marked differences in the lower portion of the cloud. More negative values are present in decoupled cases, a signature of stronger, narrower downdrafts that are forced by radiative cooling near cloud top. On the other hand, more positive $w$ skewness values are found in the coupled cases, implying a larger influence from stronger, narrower updrafts forced from surface fluxes or wind shear below. In all cases the $w$ skewness tends to become slightly positive near cloud top. This feature is likely related to clouds that protrude into the temperature inversion, and indeed coincides with cloud-top signatures in both $\theta$ and $\varepsilon$. When cloud parcels below the temperature inversion radiatively cool, they become negatively buoyant, driving upside-down shallow convection. However, when clouds that exist within the temperature inversion cool, they may not become negatively buoyant. Cloud-top positive skewness numbers suggest that different turbulent motions occur in this region. Such a signature is consistent with large eddy simulations (LES) of decoupled Arctic stratocumulus that show small-scale motions above the temperature inversion base and larger, overturning motions below (Solomon et al., 2011). 

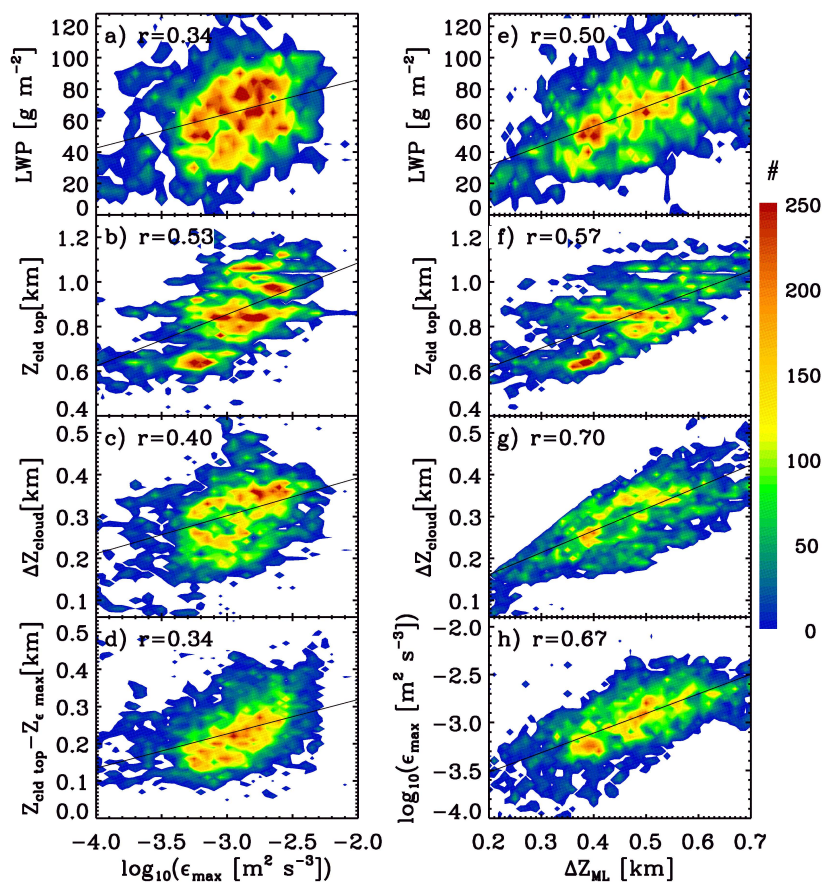

Fig. 15. Two-dimensional frequency distributions of the layermaximum turbulent dissipation rate versus (a) LWP, (b) cloud-top height, (c) cloud thickness, and (d) distance from cloud top to the height of the maximum $\varepsilon$, and the mixed-layer depth versus (e) LWP, (f) cloud-top height, (g) cloud thickness, and (h) layermaximum $\varepsilon$. Data included are only for cases where the mixedlayer base is identified to be above $0.15 \mathrm{~km}$ and all data have been subjected to a 10 min running average. Each panel includes the correlation coefficient and the least absolute deviation best linear fit to the data.

It is useful to consider how the cloud-driven mixed layer relates to cloud and turbulence properties. To do so, time periods are only considered when the mixed-layer base is above $0.15 \mathrm{~km}$ - i.e., decoupled - to ensure that the full mixed-layer depth is accounted for. In this subset of data, there are moderate positive relationships between the mixed-layer depth, cloud depth, cloud-top height, layer-maximum $\varepsilon$, and LWP (Fig. 15). Additionally, the height of layer-maximum $\varepsilon$ is typically $0.1-0.4 \mathrm{~km}$ below cloud top and moves further below top as peak $\varepsilon$ increases (Fig. 15d). Together these relationships indicate that the vertical depth of atmospheric mixing is strongly related to cloud thickness, and both are associated with, and likely determined by, the amount of turbulence. Environmental conditions such as low-level atmospheric stability may also play a role in determining the mixing depth. However, when data from Fig. 15 are partitioned according to stability below the mixed-layer base, no clear relationships are found.

There is a weak positive relationship between layermaximum $\varepsilon$ and LWP and a somewhat stronger relationship between mixed-layer depth and LWP (Fig. 15a, e). These parameters all interact in a cloud-scale feedback process where higher LWP typically contributes to enhanced cloudtop radiative cooling, which increases turbulence production, and in turn supports further cloud condensation and mixedlayer growth. In this case, most LWP values are higher than $30 \mathrm{~g} \mathrm{~m}^{-2}$, which is the approximate value at which clouds become opaque for infrared radiation. Additionally, LWP is correlated with cloud thickness (correlation coefficient of 0.7), such that increases in LWP are generally due to increases in cloud depth and not necessarily to substantial increases in cloud water content, and thus cloud opacity, near cloud top. Indeed the layer-mean liquid water content (LWP divided by cloud depth) is relatively constant in this data set at $0.23 \pm 0.10 \mathrm{~g} \mathrm{~m}^{-3}$ and shows no relationship with layermaximum $\varepsilon$ (correlation of -0.07 ). Thus, while cloud water, depth of mixing, and turbulence are clearly related, it is difficult to determine which is the primary driver of this system.

Normalized aerosol concentration profiles for all helicopter flights during the period of study (Fig. 16) offer insight into the aerosol sources that influence the stratocumulus clouds. During periods of intermittent cloud-surface coupling, $N_{>300}$ is approximately constant from cloud base down to the surface, indicating that the cloud is exposed to the same large-size aerosols that are measured near the surface. However, in the more frequent decoupled time periods, $N_{>300}$ is almost always higher within the cloud-driven mixed layer than below it. $N_{>300}$ minima (asterisks in Fig. 16b) are always observed at some height below the cloud-driven mixed-layer base, suggesting that vertical transport from below would generally not be a source of aerosol (in terms of number) to the mixed layer. Nearly all cases where the minimum $N_{>300}$ is not at the surface coincide with near-surface fogs below this height.

There are four helicopter flights during this time period that reach high altitudes either shortly before or after $(<2 \mathrm{hr})$ a low-level, stratiform cloud layer is present, providing some context for the aerosol environment that likely influenced the cloud. In all cases, $N_{>300}$ is observed to increase just at, or above, the nearby cloud top (Fig. 16c). This profile shape, combined with those for decoupled cases, suggests that air masses aloft are the primary source of these large aerosol particles for the cloud layer and that cloud-driven turbulence mixes these particles downward. One case, the 18:10 flight on 26 August (yellow in Fig. 16c), illustrates this system nicely. On this occasion the helicopter profile passes through a brief thinning of a cloud layer (see Fig. 12). $N_{>300}$ above cloud top is nearly $2 \mathrm{~cm}^{-3}$. Within the cloud itself $(0.8-1.0$ normalized height units) there is a decrease due to cloud droplet activation, but below cloud base there is a relatively steady concentration of about $1.5 \mathrm{~cm}^{-3}$ down to 0.2 normalized height units, below which is a decrease to less than half that value towards the surface. This structure is consistent with an aerosol source at cloud top, with cloud processes entraining and mixing these aerosols downward in a mixed layer that extends to 0.2 normalized height units. 

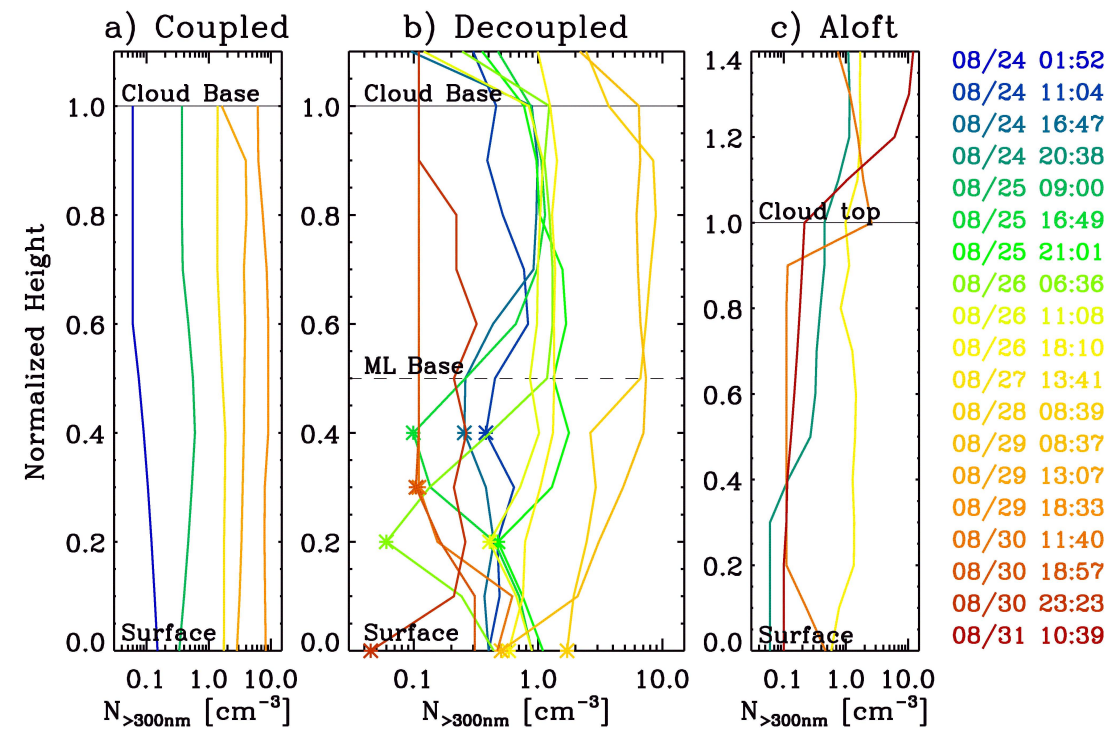

Fig. 16. Normalized vertical profiles of aerosol concentrations for particles larger than $300 \mathrm{~nm}$ measured during all individual helicopter profiles in the period of 24-31 August 2008. Profiles are distinguished by those that are (a) intermittently cloud-surface coupled, (b) decoupled, and (c) high altitude, reading above the nearby cloud top. Date and time stamps are color coded. Prior to normalization, profiles are created where the median aerosol concentration in 40-m vertical range bins is determined. Normalization in (a) and (b) is between surface (0.0) and cloud base (1.0), with the mixed-layer base (0.5) included in (b). In (b), the profile minimum below the mixed layer is designated by an asterisk. For (c), normalization is from surface (0.0) to cloud top (1.0), and the "cloud top" height is from a cloud that occurs within two hours of the profile.

Lastly, back-trajectory analyses for the full time period of study (Fig. 2) indicate that air masses generally descend over the $3-5$ days preceding their arrival at the $0.5 \mathrm{~km}$ height above Oden. Within 2-5 days' time, most trajectories also originate from latitudes south of $80^{\circ} \mathrm{N}$, the approximate latitude of the sea-ice edge at this time, where warmer temperatures are expected. Exceptions to this general picture are related to intermittently coupled periods on 24 and 25 August, when trajectories remain at or below the $0.5 \mathrm{~km}$ height for the 1-3 days during which they transect the sea-ice pack before reaching Oden. These air masses likely interacted with the ocean and sea-ice surface along their trajectories. Also, for 30-31 August back trajectories generally remain over the sea-ice pack for the previous 5 days and descend down to heights of $0.35-0.4 \mathrm{~km}$ prior to their arrival at $0.5 \mathrm{~km}$ at Oden. Nonetheless, the cloud occurring near the start of 31 August is clearly decoupled from the surface.

\section{Conclusions}

Low-level, stratiform, liquid-water-containing clouds are important for the surface energy budget of the central Arctic, imparting radiative effects that are significant with regard to sea-ice melt and freeze processes (e.g., Persson et al., 2002; Stramler et al., 2011; Sedlar et al., 2011). As many of these clouds are near opaque in the infrared, their first-order radiative properties are controlled by their presence or absence.
Thus, it is critical to understand mechanisms for maintaining supercooled liquid clouds in cold Arctic environments. Indeed, stratiform clouds are observed to be persistent in many Arctic locations (Shupe, 2011; Cesana et al., 2012), suggesting that in-cloud processes conflate to make these clouds resilient (e.g., Morrison et al., 2012). While some cloud processes are understood, there remain substantial uncertainties with regard to the relative roles of long-range advection versus local surface-based processes for supplying clouds with moisture, energy, and CCN. Additionally, the role that clouds play in vertical mixing processes that help shape the Arctic lower troposphere is still being formulated.

These cloud and atmospheric processes are examined in the sea-ice pack of the central Arctic Basin using observations from the ASCOS campaign in late summer 2008. In particular, this study focuses on a week-long period of nearly continuous stratocumulus clouds observed in late $\mathrm{Au}-$ gust near $87^{\circ} \mathrm{N}, 10^{\circ} \mathrm{W}$. An extensive suite of ground-based and aerial observations is utilized to concurrently characterize the vertical structure of cloud properties, local-scale turbulence, atmospheric mixing, and aerosol concentrations at sizes relevant for cloud droplet activation.

Key findings from this study are summarized within the context of developing a conceptual model for late summer cloud-atmosphere processes over the central Arctic sea-ice pack. While the observations used here are for a relatively short period of time at one location, their ability to simultaneously characterize so many components of the climate 
system makes them particularly valuable. Many elements of this conceptual model, listed below, are also supported by other studies:

- Central Arctic low-level stratiform clouds appear to be predominantly driven by in-cloud processes such that the clouds are self-maintaining. A variety of evidence supports this notion. First, clouds that are thermodynamically decoupled from the surface are structurally quite similar to those that are coupled to the surface, both showing little influence from the local surface. Indeed, surface turbulent heat fluxes over a predominantly sea-ice surface in late summer are weak (e.g., Persson et al., 2002; Sedlar et al., 2011), such that the surface contribution to mixed-layer processes is limited, even in cases when cloud-surface coupling does occur. Additionally, frequent moisture inversions aloft (e.g.,Tjernström, 2005; Sedlar et al., 2012) provide a moisture source for cloud maintenance that is independent of the surface. Lastly, during this period of study, the decoupled cloud state was more prevalent and persistent, occurring at least $75 \%$ of the time.

- The depth of cloud-driven mixed layers is dependent on the magnitude of turbulence and LWP. Mixed-layer depths are observed to range from 0.3 to $0.8 \mathrm{~km}$ and are strongly related to the cloud depth. Higher mixedlayer turbulence, typically caused by cloud-top radiative cooling, likely drives deeper mixing and thicker cloud layers. Other factors such as atmospheric stability below the mixed layer may also contribute to its overall depth.

- Coupling between cloud and surface is primarily driven by proximity of the cloud-driven mixed layer to the surface. Coupling with the surface is more frequent when the cloud-driven mixed layer is deeper and when the cloud itself is lower in the atmosphere. These conditions are likely related to the interplay of large-scale processes and local atmospheric structure. Under certain conditions the primary Arctic stratocumulus layer is low enough, and cold enough, to allow for sufficient vertical mixing with the surface boundary layer, resulting in cloud-surface coupling. These conditions are supported by a general cooling of the cloud-driven mixed layer in time related to cloud processes (e.g., Solomon et al., 2011).

- Surface-coupled, cloud-driven mixed layers equilibrate with the near-surface environment. Late summer, central Arctic, near-surface temperatures are relatively steady because they are regulated by the freeze-melt process of sea ice in open water. When coupling occurs, cloud-driven turbulence acts to form well-mixed layers of conserved properties such as $\theta_{\mathrm{E}}$ and $q_{\mathrm{t}}$ that are in equilibrium with these near-surface conditions.
Concentrations of cloud-active aerosol particles likely also become vertically well mixed at these times.

- Low-level air masses that are decoupled from the surface originate from large-scale, warm and moist air advection over the cold central Arctic from lower latitudes. Decoupled, cloud-driven mixed layers are generally observed to be warmer than the near-surface atmosphere, suggesting that these air masses have not significantly interacted with the colder, sea-ice surface along their upwind trajectory. Indeed, back-trajectory analyses for the decoupled cloudy air masses observed here indicate that they have generally subsided to the height at which they are observed above Oden. Additionally, moisture reservoirs aloft help to sustain cloud processes. This basic structure is consistent with warm, moist air masses originating in ice-free regions to the south, advecting into the central Arctic and riding over shallow internal boundary layers associated with the relatively cold sea-ice surface. As these air masses cool, approaching temperatures of the underlying surface, coupling becomes possible.

- Moderate differences are observed in coupled versus decoupled clouds. Clouds that are thermodynamically linked with the surface tend to be cooler and have slightly weaker in-cloud turbulence, yet often have higher LWP and IWP, possibly due to additional moisture supply from below.

- Cloud-top processes are often independent from the mixed layer but serve a critical role. Cloud top is often observed to protrude into the primary temperature inversion (e.g., Sedlar et al., 2012), supported there by plentiful moisture. Due to the static stability in this environment, water vapor condensation is forced directly by radiative cooling rather than via buoyant overturning processes. As a result, observations in this region suggest weak, shallow turbulent motions that are distinct from the primary, mixed-layer eddies. These weak motions and the slow sedimentation of cloud water can both act to moisten the mixed layer below (Solomon et al., 2011). Processes in this region are also important for entrainment of aerosols.

- Large aerosol particles that are important for stratocumulus cloud formation predominantly advect into the region within or above the cloud-driven mixed layer. The concentration of large aerosol particles is typically observed to be higher within the decoupled, cloud-driven mixed layer than at some height below. For these cases there is either a surface minimum in large aerosol concentration or a minimum between the cloud-driven mixed layer and a secondary maximum associated with near-surface fog. When cloudsurface coupling occurs, the concentration of large par- 
ticles is approximately constant from cloud base to surface. Infrequent measurements above cloud top indicate higher large aerosol concentrations aloft. These observations together suggest that aerosol particles important for these clouds have advected into the region along with warm, moist air masses aloft, consistent with back trajectories that generally show descending air masses. Only in cases when the cloud-driven mixed layer is coupled to the surface do mixed-layer aerosol concentrations relate to near-surface concentrations, but even then it is not clear that surface processes influence these concentrations.

This conceptual model, and the observations used to develop it, offers a detailed perspective on the interactions of Arctic stratiform clouds with the surface and the key role these clouds play in establishing low-level atmospheric structure over central Arctic sea ice in late summer. ASCOS, however, was simply a snapshot of this system at one place and time. Clearly more observations of this nature and complexity are needed at other locations and times of year to develop a more comprehensive conceptual model for Arctic cloudatmosphere-surface processes. In particular, more detailed observations are needed of the cloud-top environment, subcloud air motions, vertical profiles of aerosol up to the free troposphere, surface radiative effects, and spatial evolution of these properties from the ice edge out over the pack ice. To broaden our understanding of these processes beyond what is possible with observations alone, nested mesoscale and large eddy simulation models are being used to further examine the roles of turbulence, moisture inversions, cloud-surface coupling state, and phase partitioning (e.g., Solomon et al., 2009, 2011). Model studies are also needed to elucidate important processes related to large-scale advection and air mass modification over the Arctic sea ice.

Acknowledgements. This research was supported by the Office of Science (BER), US Department of Energy (DE-SC0007005, DE-SC0008794) and the US National Science Foundation (ARC1023366, ARC1203902). C. Leck and M. Tjernström were supported by the Swedish Research Council and Bert Bolin Centre for Climate Research. ASCOS was supported by the Knut and Alice Wallenberg Foundation, DAMOCLES Integrated Research Project from the European Union 6th Framework Programme, US National Science Foundation, and UK Natural Environment Research Council (NERC). The Swedish Polar Research Secretariat provided access to the icebreaker Oden and logistical support. We thank the NERC Earth Observation Data Acquisition and Analysis Service for supplying MODIS satellite imagery. Special thanks to the Oden crew and to the ASCOS team for collecting quality observational data, particularly Cathryn Birch, Paul Johnston, Sarah Norris, Maria Martin, and Cassandra Wheeler.

Edited by: G. de Leeuw

\section{References}

Barton, N. P., Klein, S. A., Boyle, J. S., and Zhang, Y. Y.: Arctic synoptic regimes: Comparing domain wide Arctic cloud observations with CAM4 and CAM5 during similar dynamics, J. Geophys. Res, 117, D15205, doi:10.1029/2012JD017589, 2012.

Birmili, W., Stratmann, F., and Wiedensohler, A.: Design of a DMA-based size spectrometer for a large particle size range and stable operation, J. Aerosol Sci., 30 549-554, 1999.

Birch, C. E., Brooks, I. M., Tjernström, M., Shupe, M. D., Mauritsen, T., Sedlar, J., Lock, A. P., Earnshaw, P., Persson, P. O. G., Milton, S. F., and Leck, C.: Modeling atmospheric structure, cloud and their response to $\mathrm{CCN}$ in the central Arctic: ASCOS case studies, Atmos. Chem. Phys., 12, 3419-3435, doi:10.5194/acp-12-3419-2012, 2012.

Bouniol, D., Illingworth, A. J., and Hogan, R. J.: Deriving turbulent kinetic energy dissipation rate within clouds using ground based $94 \mathrm{GHz}$ radar, Preprints, 31st Conf. on Radar Meteorology, Seattle, WA, Am. Meteor. Soc., 193-196, available at: http://ams.confex.com/ams/pdfpapers/63826.pdf, 2003.

Cesana, G., Kay, J. E., Chepfer, H., English, J. M., and de Boer, G.: Ubiquitous low-level liquid-containing Arctic clouds: New observations and climate model constraints from CALIPSO-GOCCP, Geophys. Res. Lett., 39, L20804, doi:10.1029/2012GL053385, 2012.

Chang, R. Y.-W., Leck, C., Graus, M., Müller, M., Paatero, J., Burkhart, J. F., Stohl, A., Orr, L. H., Hayden, K., Li, S.-M., Hansel, A., Tjernström, M., Leaitch, W. R., and Abbatt, J. P. D.: Aerosol composition and sources in the central Arctic Ocean during ASCOS, Atmos. Chem. Phys., 11, 10619-10636, doi:10.5194/acp-11-10619-2011, 2011.

Comiso, J., Parkinson, C., Gersten, R., and Stock, L. S.: Accelerated decline in the Arctic sea ice cover, Geophys. Res. Lett., 35, L01703, doi:10.1029/2007GL031972, 2008.

Curry, J. A. and Herman, G. F.: Relationships between large-scale heat and moisture budgets and the occurrence of Arctic stratus clouds, Mon. Wea. Rev., 113, 1441-1457, 1985.

Curry, J. A., Ebert E. E., and Herman, G. F.: Mean the turbulence structure of the summertime Arctic cloudy boundary layer, Q. J. Roy. Meteor. Soc., 114, 715-746, 1988.

Curry, J. A., Hobbs, P. V., King, M. D., Randall, D. A., Minnis, P., Isaac, G. A., Pinto, J. O., Uttal, T., Bucholtz, A., Cripe, D. G., Gerber, H., Fairall, C. W., Garrett, T. J., Hudson, J., Intrieri, J. M., Jakob, C., Jensen, T., Lawson, P., Marcotte, D., Nguyen, L., Pilewskie, P., Rangno, A., Rogers, D. C., Strawbridge, K. B., Valero, F. P. J., Williams, A. G., and Wylie, D.: FIRE Arctic Clouds Experiment, B. Am. Meteorol. Soc., 81, 5-30, 2000.

de Boer, G., Eloranta, E., and Shupe, M. D.: Arctic mixed-phase stratiform cloud properties from multiple years of surface-based measurements at two high-latitude locations, J. Atmos. Sci., 66, 2874-2887, 2009.

de Boer, G., Chapman, W., Kay, J. E., Medeiros, B., Shupe, M. D., Vavrus, S., and Walsh, J.: A characterization of the present-day Arctic atmosphere in CCSM4, J. Climate, 25, 2676-2695, 2012.

Draxler, R. R. and Rolph, G. D.: HYSPLIT (HYbrid Single-Particle Lagrangian Integrated Trajectory) Model access via NOAA ARL READY Website http://ready.arl.noaa.gov/HYSPLIT.php (last access: 7 April 2010), NOAA Air Resources Laboratory, Silver Spring, MD, 2011. 
Francis, J. A. and Hunter, E.: New insight into the disappearing Arctic sea ice, EOS, Trans. Amer. Geophys. Union, 87, 509-511, 2006.

Fridlind, A. M., van Diedenhoven, B., Ackerman, A. S., Avramov, A., Mrowiec, A., Morrison, H., Zuidema, P., and Shupe, M. D.: A FIRE-ACE/SHEBA case study of mixed-phase Arctic boundarylayer clouds: Entrainment rate limitations on rapid primary ice nucleation processes, J. Atmos. Sci., 69, 365-389, 2012.

Heintzenberg, J. and Leck, C.: The summer aerosol in the central Arctic 1991-2008: did it change or not?, Atmos. Chem. Phys., 12, 3969-3983, doi:10.5194/acp-12-3969-2012, 2012.

Herman, G. F. and Curry, J. A.: Observational and theoretical studies of solar radiation in Arctic stratus clouds, J. Clim. Appl. Meteor., 23, 5-24, 1984.

Hill, M. K., Brooks, B. J., Norris, S. J., Smith, M. H., Brooks, I. M., and de Leeuw, G.: A compact lightweight aerosol spectrometer probe (CLASP), J. Atmos. Ocean. Tech., 25, 1996-2006, 2008.

Hobbs, P. V. and A. L. Rangno: Microstructures of low and middlelevel clouds over the Beaufort Sea, Q. J. Roy. Meteor. Soc., 124, 2035-2071, 1998.

Hogan, R. J., Grant, A. L., Illingworth, A. J., Pearson, G. N., and O'Connor, E. J.: Vertical velocity variance and skewness in clear and cloud-topped boundary layers as revealed by Doppler lidar, Q. J. Roy. Meteor. Soc., 135, 635-643, 2009.

Holland, M. M. and Bitz, C. M.: Polar amplification of climate change in coupled models, Clim. Dynam., 21, 221-232, 2003.

Jiang, H., Cotton, W. R., Pinto, J. O., Curry, J. A., and Weissbluth, M. J.: Cloud resolving simulations of mixed-phase Arctic stratus observed during BASE: Sensitivity to concentrations of ice crystals and large-scale heat and moisture advection, J. Atmos. Sci., 57, 2105-2117, 2000.

Karlsson, J. and Svensson, G.: The simulation of Arctic clouds and their influence on the winter surface temperature in present-day climate in the CMIP3 multi-model dataset, Clim. Dynam., 36, 623-635, 2011.

Kay, J. E. and Gettelman, A.: Cloud influence on and response to seasonal Arctic sea ice loss, J. Geophys Res., 114, D18204, doi:10.1029/2009JD011773, 2009.

Kay, J. E., L'Ecuyer, E. T., Gettelman, A., Stephens, G., and O’Dell, C.: The contribution of cloud and radiation anomalies to the 2007 Arctic sea ice extent minimum, Geophys. Res. Lett., 35, L08503, doi:10.1029/2008GL033451, 2008.

Kupiszewski, P., Leck, C., Tjernström, M., Sjogren, S., Sedlar, J., Graus, M., Müller, M., Brooks, B., Swietlicki, E., Norris, S., and Hansel, A.: Vertical profiling of aerosol particles and trace gases over the central Arctic Ocean during summer, Atmos. Chem. Phys. Discuss., 13, 10395-10461, doi:10.5194/acpd-13-103952013, 2013.

Lance, S., Shupe, M. D., Feingold, G., Brock, C. A., Cozic, J., Holloway, J. S., Moore, R. H., Nenes, A., Schwarz, J. P., Spackman, J. R., Froyd, K. D., Murphy, D. M., Brioude, J., Cooper, O. R., Stohl, A., and Burkhart, J. F.: Cloud condensation nuclei as a modulator of ice processes in Arctic mixed-phase clouds, Atmos. Chem. Phys., 11, 8003-8015, doi:10.5194/acp-11-80032011, 2011.

Leck, C. and Persson, C.: Seasonal and short-term variability in dimethyl sulfide, sulfur dioxide and biogenic sulfur and sea salt aerosol particles in the Arctic marine boundary layer during summer and autumn, Tellus, 48B, 272-299, 1996.
Leck, C. and Bigg, E. K.: Source and evolution of the marine aerosol - A new perspective, Geophys. Res. Lett., 32, L19803, doi:10.1029/2005GL023651, 2005.

Leck, C., Norman, M., Bigg, E. K., and Hillamo, R.: Chemical composition and sources of the high Arctic aerosol relevant for fog and cloud formation, J. Geophys. Res., 107, 4135, doi:10.1029/2001JD001463, 2002.

Leck, C., Tjernström, M., Matrai, P., Swietlicki, E., and Bigg, E. $\mathrm{K}$.: Can marine micro-organisms influence melting of the Arctic pack ice?, Eos, 85, 25-36, 2004.

Levasseur, M., Gosselin, M., and Michaud, S.: A new source of dimethylsulfide (DMS) for the arctic atmosphere: ice diatoms, Marine Biol., 121, 381-387, 1994.

Li, S. M., Barrie, L. A., and Sirois, A.: Biogenic sulphur aerosol in the Arctic troposphere: 2. Trends and seasonal variations, J. Geophys. Res., 98, 20623-20631, 1993.

Liu, Y., Key, J. R., Francis, J. A., and Wang, X.: Possible causes of decreasing cloud cover in the Arctic winter, 1982-2000, Geophys. Res. Lett., 34, L14705, doi:10.1029/2007GL030042, 2007.

Liu, Y., Key, J. R., and Wang, W.: The influence of changed in cloud cover on recent surface temperature trends in the Arctic, J. Climate, 21, 705-715, 2008.

Martin, M., Chang, R. Y.-W., Sierau, B., Sjogren, S., Swietlicki, E., Abbatt, J. P. D., Leck, C., and Lohmann, U.: Cloud condensation nuclei closure study on summer arctic aerosol, Atmos. Chem. Phys., 11, 11335-11350, doi:10.5194/acp-11-11335-2011, 2011.

McFarquhar, G. M., Ghan, S., Verlinde, J., Korolev, A., Strapp, J. W., Schmid, B., Tomlinson, J., Wolde, M., Brooks, S., Collins, D., Cziczo, D., Dubey, M., Fan, J., Flynn, C., Gultepe, I., Hubbe, J., Gilles, M., Kok, G., Laskin, A., Lawson, P., Liu, P., Liu, X., Lubin, D., Mazzoleni, C., Macdonald, A.-M., Moffet, R., Morrison, H., Ovchinnikov, M., Ronfeld, D., Shupe, M. D., Turner, D. D., Xie, S., and Zelenyuk, A.: Indirect and Semi-Direct Aerosol Campaign (ISDAC): The impact of Arctic aerosols on clouds, B. Am. Meteorol. Soc., 92, 183-201, doi:10.1175/2010BAMS2935.1, 2011.

Moran, K. P., Martner, B. E., Post, M. J., Kropfli, R. A., Welsh, D. C., and Widener, K. B.: An unattended cloud-profiling radar for use in climate research, B. Am. Meteorol. Soc., 79, 443-455, 1998.

Morrison, H., de Boer, G., Feingold, G., Harrington, J., Shupe, M. D., and Sulia, K.: Resilience of persistent Arctic mixed-phase clouds, Nat. Geosci., 5, 11-17, doi:10.1038/NGEO1332, 2012.

Nicholls, S.: The dynamics of stratocumulus: Aircraft observations and comparisons with a mixed layer model, Q. J. Roy. Meteor. Soc., 110, 783-820, 1984.

Orellana, M. V., Matrai, P. A., Leck, C., Rauschenberg, C. D., Lee, A. M., and Coz, E.: Marine microgels: a source of $\mathrm{CCN}$ in the high Arctic, PNAS, 33, 13612-13617, doi:10.1073/pnas.1102457108, 2011.

Perovich, D. K., Richter-Menge, J. A., Jones, K. F., and Light, B.: Sunlight, water, and ice: extreme Arctic sea ice melt during the summer of 2007, Geophys. Res. Lett., 35, L11501, doi:10.1029/2008GL034007, 2008.

Persson, P. O. G., Fairall, C. W., Andreas, E. L., Guest, P. S., and Perovich, D. K.: Measurements near the Atmospheric surface Flux Group tower at SHEBA: near-surface conditions and surface energy budget, J. Geophys. Res., 107, 1-21, doi:10.1029/2000JC000705, 2002. 
Pinto, J. O.: Autumnal mixed-phase cloudy boundary layers in the Arctic, J. Atmos. Sci., 55, 2016-2038, 1998.

Roberts, G. C. and Nenes, A.: A continuous-flow streamwise thermal-gradient $\mathrm{CCN}$ chamber for atmospheric measurements, Aerosol Sci. Technol., 39, 206-221, 2005.

Rolph, G. D.: Real-time Environmental Applications and Display sYstem (READY) Website http://ready.arl.noaa.gov (last access: 7 April 2010), NOAA Air Resources Laboratory, Silver Spring, MD, 2011.

Schweiger, A. J., Lindsay, R. W., Vavrus, S., and Francis, J. A.: Relationships between Arctic sea ice and clouds during fall, J. Climate, 21, 4799-4810, 2008.

Sedlar, J., Tjernström, M., Mauritsen, T., Shupe, M. D., Brooks, I. M., Persson, P. O. G., Birch, C. E., Leck, C., Sirevaag, A., and Nicolaus, M.: A transitioning Arctic surface energy budget: the impacts of solar zenith angle, surface albedo and cloud radiative forcing, Clim. Dynam., 37, 1643-1660, 2011.

Sedlar, J., Shupe, M. D., and Tjernström, M.: On the relationship between thermodynamic structure, cloud top, and climate significance in the Arctic, J. Climate, 25, 2374-2393, 2012.

Serreze, M., Barrett, A., Stroeve, J., Kindig, D., and Holland, M.: The emergence of a surface-based Arctic amplification, Cryosphere, 3, 11-19, 2009.

Shupe, M. D.: A ground-based multiple remote-sensor cloud phase classifier, Geophys. Res. Lett., 34, L2209, doi:10.1029/2007GL031008, 2007.

Shupe, M. D.: Clouds at Arctic atmospheric observatories. Part 2: Thermodynamic phase characteristics, J. Appl. Meteorol., 50 645-661, 2011.

Shupe, M. D. and Intrieri, J. M.: Cloud radiative forcing of the Arctic surface: The influence of cloud properties, surface albedo, and solar zenith angle, J. Climate, 17, 616-628, 2004.

Shupe, M. D., Uttal, T., and Matrosov, S. Y.: Arctic cloud microphysics retrievals from surface-based remote sensors at SHEBA, J. Appl. Meteorol., 44, 1544-1562, 2005.

Shupe, M. D., Matrosov, S. Y., and Uttal, T.: Arctic mixed-phase cloud properties derived from surface-based sensors at SHEBA, J. Atmos. Sci., 63, 697-711, 2006.

Shupe, M. D., Kollias, P., Persson, P. O. G., and McFarquhar, G. M.: Vertical motions in Arctic mixed-phase stratiform clouds, J. Atmos. Sci., 65, 1304-1322, 2008.

Shupe, M. D., Brooks, I. M., and Canut, G.: Evaluation of turbulent dissipation rate retrievals from Doppler Cloud Radar, Atmos. Meas. Tech., 5, 1375-1385, doi:10.5194/amt-5-1375-2012, 2012.

Shupe, M. D., Turner, D. D., Walden, V. P., Bennartz, R., Cadeddu, M., Castellani, B., Cox, C., Hudak, D., Kulie, M., Miller, N., Neely III, R. R., Neff, W., and Rowe, P.: High and Dry: New observations of tropospheric and cloud properties above the Greenland Ice Sheet, B. Am. Meteorol. Soc., 94, 169-186, doi:10.1175/BAMS-D-11-00249.1, 2013.

Solomon, A., Morrison, H., Persson, P. O. G., Shupe, M. D., and Bao, J.-W.: Investigations of microphysical parameterizations of snow and ice in Arctic clouds during M-PACE through modelobservation comparison, Mon. Weather Rev., 137, 3110-3128, 2009.

Solomon, A., Shupe, M. D., Persson, P. O. G., and Morrison, H.: Moisture and dynamical interactions maintaining decoupled Arctic mixed-phase stratocumulus in the presence of a humidity inversion, Atmos. Chem. Phys., 11, 10127-10148, doi:10.5194/acp-11-10127-2011, 2011.

Stramler, K., Del Genio, A., and Rossow, W.: Synoptically driven Arctic winter states, J. Climate, 47, 1747-1762, 2011.

Stroeve, J., Holland, M., Meier, W., Scambos, T., and Serreze, M.: Arctic sea ice decline: Faster than forecast, Geophys. Res. Lett., 34, L09501, doi:10.1029/2007GL029703, 2007.

Stroeve, J. C., Serreze, M. C., Holland, M. M., Kay, J. E., Maslanik, J., and Barrett, A. P.: The Arctic's rapidly shrinking sea ice cover: a research synthesis, Clim. Change, 110, 1005-1027, 2012.

Tjernström, M.: The summer Arctic boundary layer during the Arctic Ocean Experiment 2001 (AOE-2001), Bound.-Lay. Meteorol., 117, 5-36, 2005.

Tjernström, M., Leck, C., Persson, P. O. G., Jensen, M. L., Oncley, S. P., and Targino, A.: The summertime Arctic atmosphere: meteorological measurements during the Arctic Ocean Experiment (AOE-2001), B. Am. Meteorol. Soc., 85, 1305-1321, 2004.

Tjernström, M., Sedlar, J., and Shupe, M. D.: How well do regional climate models reproduce radiation and clouds in the Arctic? An evaluation of ARCMIP simulations, J. Appl. Met. Clim., 47, 2405-2422, 2008.

Tjernström, M., Birch, C. E., Brooks, I. M., Shupe, M. D., Persson, P. O. G., Sedlar, J., Mauritsen, T., Leck, C., Paatero, J., Szczodrak, M., and Wheeler, C. R.: Meteorological conditions in the central Arctic summer during the Arctic Summer Cloud Ocean Study (ASCOS), Atmos. Chem. Phys., 12, 6863-6889, doi:10.5194/acp-12-6863-2012, 2012.

Tjernström, M., Leck, C., Birch, C. E., Brooks, B. J., Brooks, I. M., Bäcklin, L., Chang, R. Y.-W., Granath, E., Graus, M., Hansel, A., Heintzenberg, J., Held, A., Hind, A., de la Rosa, S., Johnston, P., Knulst, J., de Leeuw, G., Di Liberto, L., Martin, M., Matrai, P. A., Mauritsen, T., Müller, M., Norris, S. J., Orellana, M. V., Orsini, D. A., Paatero, J., Persson, P. O. G., Gao, Q., Rauschenberg, C., Ristovski, Z., Sedlar, J., Shupe, M. D., Sierau, B., Sirevaag, A., Sjogren, S., Stetzer, O., Swietlicki, E., Szczodrak, M., Vaattovaara, P., Wahlberg, N., Westberg, M., and Wheeler, C. R.: The Arctic Summer Cloud-Ocean Study (ASCOS): overview and experimental design, Atmos. Chem. Phys. Discuss., 13, 1354113652, doi:10.5194/acpd-13-13541-2013, 2013.

Turner, D. D.: Arctic mixed-phase cloud properties from AERI lidar obsrvations: Algorithm and results from SHEBA, J. Appl. Meteor., 44, 427-444, 2005.

Uttal, T., Curry, J. A., McPhee, M., Perovich, D., Moritz, R. E., Maslanik, J. A., Guest, P. S., Stern, H. L., Moore, J. A., Turenne, R., Heiberg, A., Serreze, M. C., Wylie, D. P., Persson, P. O. G., Paulson, C. A., Halle, C. Morison, J. H., Wheeler, P. A., Makshtas, A., Welch, H., Shupe, M. D., Intrieri, J. M., Stamnes, K., Lindsey, R. W., Pinkel, R., Pegau, W. S., Stanton, T. P., and Grenfeld, T. C.: Surface Heat Budget of the Arctic Ocean, B. Am. Meteorol. Soc., 83, 255-275, 2002.

Vavrus, S.: The impact of cloud feedbacks on Arctic climate under greehouse forcing, J. Climate, 17, 603-615, 2004.

Vavrus, S., Holland, M. M., and Bailey D. A.: Changes in Arctic clouds during intervals of rapid sea ice loss, Clim. Dynam., 36, 1475-1489, 2011.

Verlinde, J., Harrington, J. Y., McFarquhar, G. M., Yannuzzi, V. T., Avramov, A., Greenberg, S., Johnson, N., Zhang, G., Poellot, M. R., Matther, J. H., Turner, D. D., Eloranta, E. W., Zak, B. D., Prenni, A. J., Daniel, J. S., Kok, G. L., Tobin, D. C., Holz, R., 
Sassen, K., Spangenberg, D., Minnis, P., Tooman, T. P., Ivey, M. D., Richardson, S. J., Bahrmann, C. P., Shupe, M. D., Demott, P. J., Heymsfield, A. J., and Schofield, R.: The Mixed-Phase Arctic Cloud Experiment, B. Am. Meteorol. Soc., 88, 205-221, 2007.

Wang, X. and Key, J. R.: Recent trends in Arctic surface, cloud, and radiation properties from space, Science, 299, 1725-1728, 2003.

Westwater, E. R., Han, Y., Irisov, V. G., Leusky, V., Kadygrov, E. N., and Viasankin, S. A.: Remote sensing of boundary layer temperature profiles by a scanning $5-\mathrm{mm}$ microwave radiometer and RASS: Comparison experiments, J. Atmos. Ocean. Tech., 16, 805-818, 1999.
Westwater, E. R., Han, Y., Shupe, M. D., and Matrosov, S. Y.: Analysis of integrated cloud liquid and precipitable water vapor retrievals from microwave radiometers during SHEBA, J. Geophys. Res, 106, 32019-32030, 2001. 